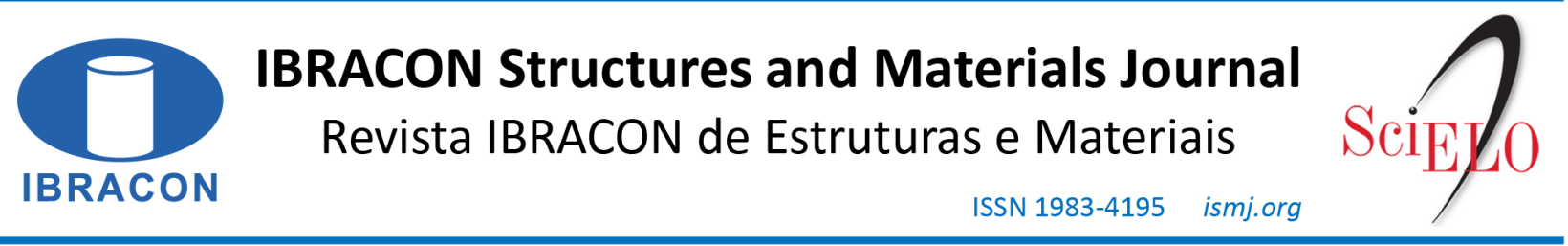

ORIGINAL ARTICLE

\title{
Curved bridges live load bending moment distribution using straight and curved girders
}

\section{Distribuição de momento fletor devido a carga móvel em pontes curvas utilizando longarinas retas e curvas}

\author{
Arthur da Silva Rebouças ${ }^{\mathrm{a}}$ (D) \\ José Neres da Silva Filho ${ }^{\mathrm{b}}$ (D) \\ Rodrigo Barros ${ }^{\mathrm{b}}$ (D) \\ Yngrid Rayane Freitas Nascimento ${ }^{\mathrm{b}}$ (D) \\ Pedro Mitzcun Coutinho ${ }^{\mathrm{b}}$
}

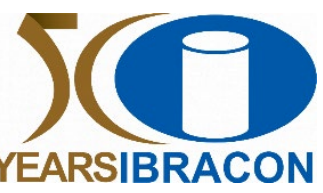

Received 11 September 2020

Accepted 20 August 2021 anstituto Federal de Educação, Ciência e Tecnologia do Rio Grande do Norte - IFRN, São Paulo do Potengi, RN, Brasil

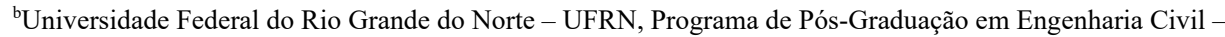
PEC/UFRN, Natal, RN, Brasil

\begin{abstract}
The present study focuses on comparative parametric analysis of curved precast concrete bridges using straight and curved I-girders. The live load bending moment distribution for girders was studied using the bridge curvature and its relationship with the results obtained for a straight bridge. FEM 3D models were developed with restrictions on the transverse live load positions and with two different load models types: HL-93 (AASHTO) and TB-450 (NBR 7188, 2013). The parametric analysis results were calculated using the Modification Factor (MF) and the Bending Moment Distribution Factor (BMDF), calculated from the structural analysis of each model at the midspan. Globally, an increase was found in the total bending moment for the curved bridge models in relation to the straight bridge. In the examples herein studied, the larger the bending radius, the larger the maximal bending moment in the bridge center. For the external girders, the MF increases with the increase of the $\mathrm{L} / \mathrm{R}$. For the internal ones, the MF decreases with the increase of the $\mathrm{L} / \mathrm{R}$. In addition, the occurrence of "Load Shift" was different from the rigid body behavior, for there was demonstrated a different bending moment variation between external girder (G1) in relation to its adjacent (G2). Therefore, the structural behavior of straight (SG) and curved girders (CG) was analyzed, revealing that, in the SG, a significant gap occurred in the BMDF between G1 and G2 girders for all curvatures. For $\mathrm{L} / \mathrm{R}=0.6$, it caused a difference of $17.8 \%$ in the BMDF between the $\mathrm{G} 1$ and $\mathrm{G} 2$ girders, while on the curved girders, a difference of only $6.6 \%$ was found.
\end{abstract}

Keywords: bridges, live loads, curvature, bending moment distribution, FEM.

Resumo: o presente estudo foca na análise paramétrica comparativa de pontes curvas utilizando utilizando longarinas retas e curvas pré-moldadas. As análises foram baseadas na distribuição transversal de momento fletor para a longarinas, na variação da curvatura da ponte e na relação desses parâmetros com os resultados obtidos em uma ponte reta. Foram desenvolvidos FEM 3D models com restrições nas posições transversais da carga-móvel e com dois tipos diferentes de modelos de carga: HL-93 e NBR 7187. Os resultados da análise paramétrica foram determinados utilizando o Fator de Modificação (FM) e o Fator de Distribuição de Momento Fletor (FDMF), calculadas a partir da análise estrutural de cada modelo na posição longitudinal do meio do vão. No âmbito global, contatou-se um aumento do momento fletor total nos modelos de ponte curva em relação à reta. Nos exemplos estudados, quanto maior o raio de curvatura, maior foi o momento fletor máximo no meio do vão da ponte. O valor de FM varia linearmente. Para as longarinas externas o

Corresponding author: Arthur da Silva Rebouças. E-mail: arthur.reboucas@ifrn.edu.br

Financial support: None.

Conflict of interest: Nothing to declare. 
FM aumenta com o aumento do L/R, já para as internas, o FM diminui com o aumento do L/R. Além disso, foi comprovada a ocorrência de "Load Shift" diferente do comportamento de corpo rígido, tendo em vista a variação diferenciada de momento fletor para a longarina externa G1 em relação a sua adjacente G2. Constatou-se uma diferença considerável de comportamento estrutural entre as longarinas retas e curvas, tendo em vista que nas SG ocorreu uma diferença significativa de FDMF entre a longarina G1 e a G2 para todas as curvaturas, o que não ocorreu para as $\mathrm{CG}$. $\mathrm{Para} \mathrm{L} / \mathrm{R}=0.6$, observou-se uma diferença de $17.8 \%$ no FDMF entre as longarinas G1 e G2 retas, já nas longarinas curvas, a diferença foi de apenas $6.6 \%$.

Palavras-chave: pontes, cargas móveis, curvatura, distribuição de momento fletor, Método dos Elementos Finitos.

How to cite: A. S. Rebouças, J. N. Silva Filho, R. Barros, Y. R. F. Nascimento, and P. M. Coutinho, "Live Load Radial Moment Distribution for curved bridges using straight and curved girders," Rev. IBRACON Estrut. Mater., vol. 15, no. 2, e15208, 2022, https://doi.org/10.1590/S1983-41952022000200008

\section{INTRODUCTION}

According to the World Economic Forum [1], the number of cars in the world was 1.1 billion. It is expected that this number will continue to grow, possibly doubling until 2040, reaching over 2.0 billion. In such a scenario, more robust and efficient transportation logistics is required, which must be met by building roads, railroads, bridges, and viaducts. In large cities, the need for mobility and the difficulty of interposing obstacles in restricted spaces makes the specification of bridges and curved viaducts designs frequent.

Previously, according to Amorn et al. [2], curved bridges were usually built using a set of straight rails, forming a sequence of straight stretches within the curve. The fabrication of curved rails in the plane was very laborious, costly, and the structural analysis of this type of geometry was considered complex. Nowadays, with the development of the manufacturing equipment and industry, the curvature in the plane does not impose as many difficulties. In addition, in relation to structural analysis, the advance of software tools allows the modeling and analysis of curved bridges in a relatively simple manner.

According to Alawneh [3], in the last thirty years, steel girder bridges have dominated the construction of curved bridges due to advantages such as speed of construction, relative flexibility and light weight. However, the prestressed concrete girders bridges are a viable alternative since they are widely used in bridges with straight longitudinal design and are considerably stiffer than steel ones.

Hence, the present study focuses on the parametric comparative analysis of bridges with curved longitudinal layout using prefabricated "I" section, straight girders, and curved ones. The analyses were based on the crosssectional distribution of the girders bending moment, the variation of the bridge curvature and the relationship of these parameters with the results obtained in a straight bridge. The results were obtained from 3D models executed with restrictions on the transverse positions of the live load and applying two different vehicle types. They indicated several advantages in the structural behaviour of curved girders compared to straight girders.

\section{STRUCTURAL BEHAVIOR OF CURVED BRIDGES}

The bridge with curved longitudinal layout has different structural behaviour from the straight due to the center of gravity's position being located outside the line connecting the extreme supports, generating an eccentricity in relation to this axis, and consequently an overall torsional trend around the supports (Figure 1). The main property of the superstructure of curved bridges is curvature, which can be measured as the ratio between the arc length of the bridge centerline $\left(\mathrm{L}_{\mathrm{a}}\right)$ and the radius between this arc and the center $(\mathrm{R})$. According to PCI Bridge Design Manual [4], although it is an arch, the center of gravity of the surface of bridge deck is different from the center of gravity of an arch due to the portion of area on the part of the deck that is above the center line. This portion of area is larger than the lower portion, moving the center of gravity closer to the center line and increasing the eccentricity in relation to the line connecting the supports.

In addition, due to the eccentricity between the CG of the bridge and the line connecting the supports, the torsion will be maximum in the supports, which generates the need to design supports that have torsional stiffness. 


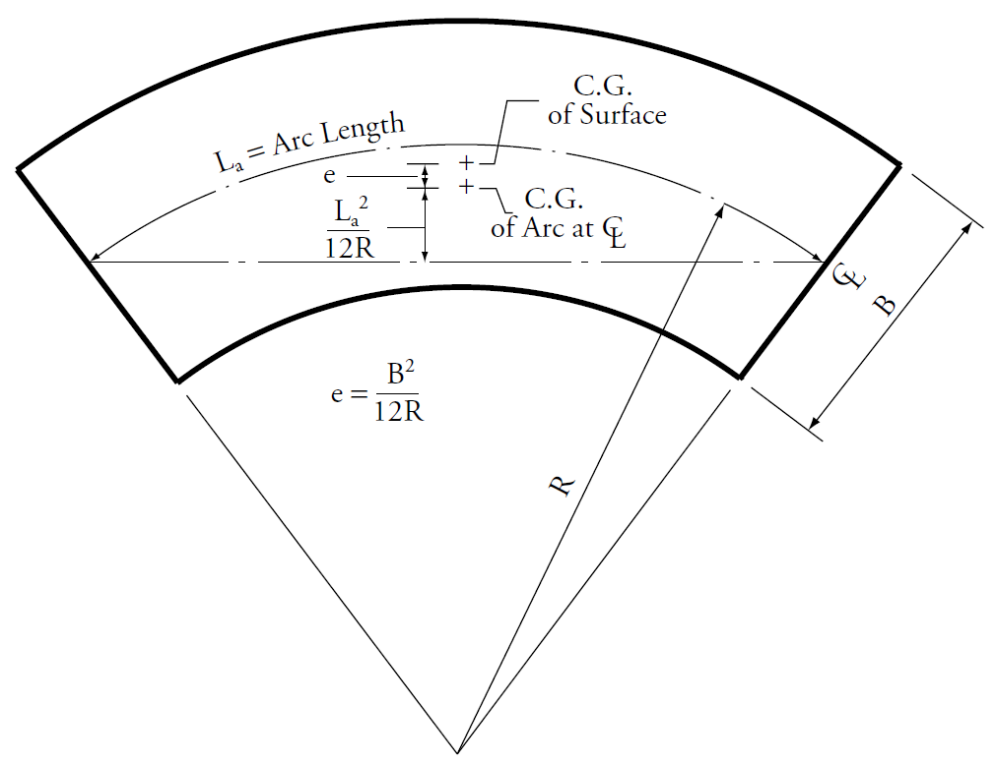

Figure 1. Geometric Properties of a curved bridge deck. PCI Bridge Design Manual [4].

Accordingly, for any load applied in the vertical plane, bending and torsion forces arise in a coupled way, along the structural element. This interaction between torsion and bending is mandatory, since it comes from the equilibrium conditions of a curved beam element, which in this case represents the global equilibrium of the bridge. Figure 2 shows an infinitesimal element of a curved beam loaded only in the normal direction to the horizontal plane, as well as the internal forces generated by this loading. Equations (1), (2) and (3) denote the structural behavior of a curved beam element. Equations (1) and (2) depend directly on the radius of curvature (R)

$\frac{d V}{d s}=-p$

$\frac{d M}{d s}=V-\frac{T}{R}$

$\frac{d T}{d s}=t+\frac{M}{R}$

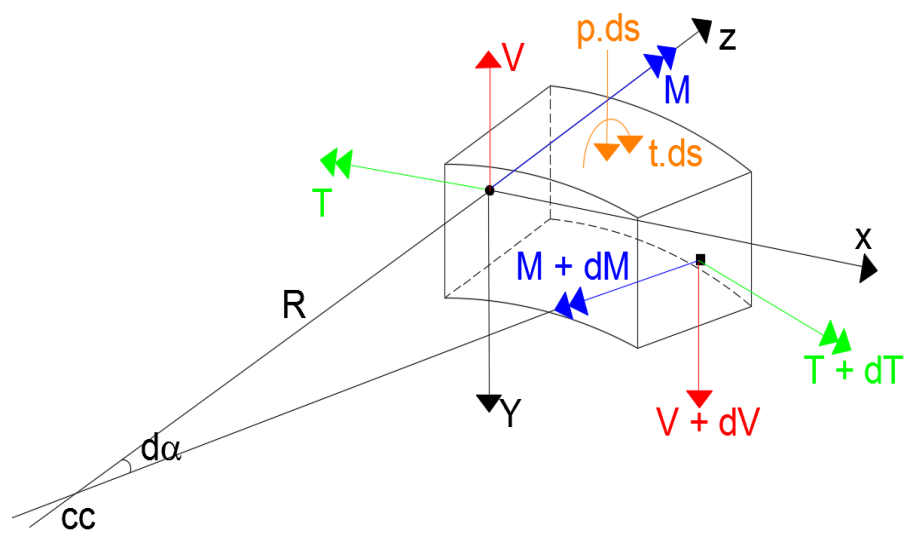

Figure 2. Structural behavior of a curved beam element. 


\section{EXISTING SYSTEMS FOR CURVED PRECAST CONCRETE GIRDERS BRIDGES}

To design prestressed concrete curved bridges the designers can use various structural configurations. In bridges with open cross section, in most cases, straight beams are used within the curved bridge layout due to their simplicity of construction. However, it is also possible to use precast concrete curved girders for this layout. As already mentioned, Alawneh [3] developed a methodology for the construction of precast concrete curved girders with straight sections connected in predefined positions to achieve the desired curvature. Figure 3 shows the proposed geometry.

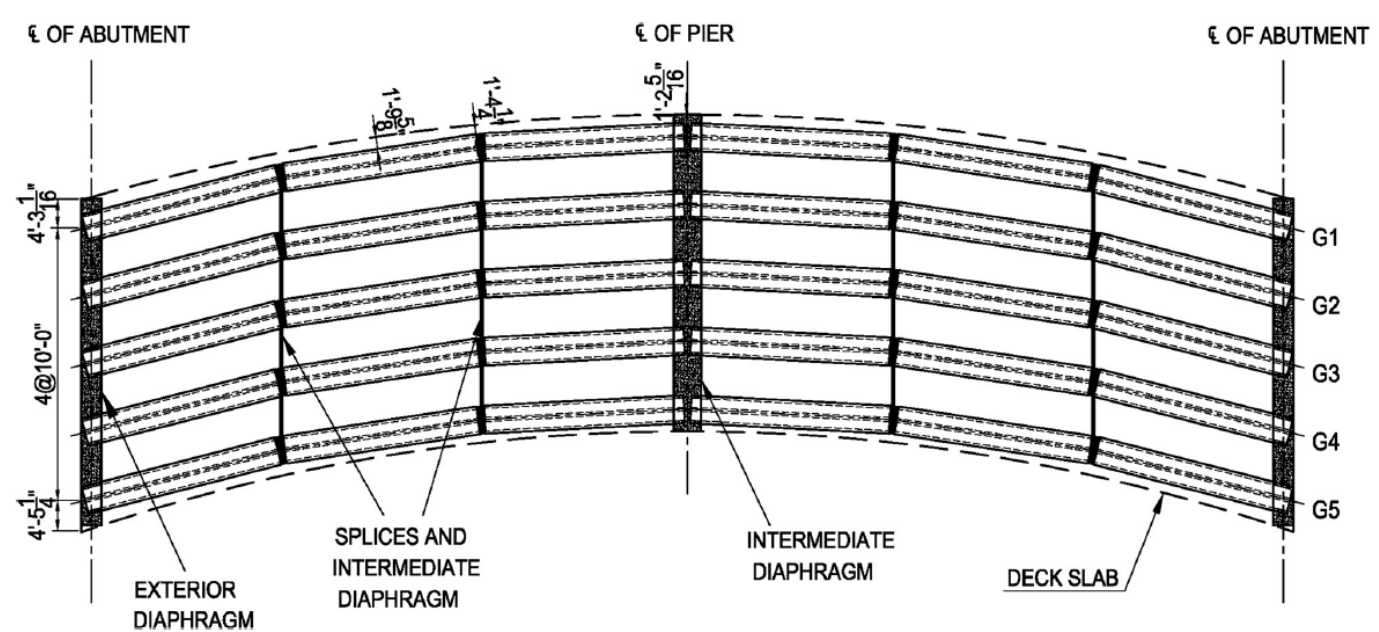

Figure 3. Geometry of Curved Precast Concrete Girders Bridges. Alawneh et al. [3]

According to Cho et al. [5], the application of curvature in precast prestressed concrete girders is very advantageous, since the steel girders, mostly used in this type of curved layout, have low stiffness to warping. Another factor that contributes to the use of concrete girders is better stability during assembly compared to steel girders.

\section{BENDING MOMENT DISTRIBUTION PARAMETERS IN CURVED BRIDGES}

In bridges with more than two girders, the distribution of internal forces depends on the stiffness of the structural elements. It was initially decided to investigate which are the main factors influencing the bending moment distribution for the curved bridges girders, especially regarding the magnitude of the effect that is allocated to each of them.

Brockenbrough [6] tested the impact of several parameters on the distribution of effort in open section curved bridges and concluded that variations in the girder stiffness and in the spacing of the diaphragms have a small effect on this distribution, but that the central angle per span, which includes the combined effect of curvature and span length, and the girders spacing, have the greatest effects. Kim et al. [7] pointed out that the key parameters to study the distribution of bending moment in curved bridges are the radius, the girders spacing, the span length and the spacing between the diaphragms.

Therefore, it was decided to focus on the curvature (relation between span length (L) and radius (R)) according to Figure 1, varying it within limit parameters and fixing all other parameters mentioned above, to analyze the direct impact of the curvature on the bending moment distribution for each girder

\section{MODELS}

A curved bridge is basically a straight bridge to which an eccentricity applied in relation to the line connecting the extreme supports. In most cases, this curvature is imposed using a fixed curvature along the entire length of the bridge.

The AASHTO [8] defines that the central angle of the bridge should vary from $12^{\circ}$ to $34^{\circ}$, due to the limitation of torsion stiffness in open sections. These conditions were used as the basis for the development of the models under study. Four groups of bridge models were created maintaining all physical and geometric parameters while varying solely the curvature (L/R).

In each curved bridge model, straight girders (SG) and curved girders (CG) geometries defined with the same height and cross section were applied. In addition, a bridge model with straight longitudinal layout (SB) was used as a reference for the comparative analyses that were performed. In this group, only one model was created, with the same cross section as the curved bridge models. All models are shown in Table 1. 


\subsection{Materials}

The same material properties, defined according to current design practices, were used in all models. The structural analysis was carried out in the linear static analysis, with the properties adopted for all models presented in Table 2.

Table 1. Structural analysis models

\begin{tabular}{|c|c|c|}
\hline $\mathbf{L} / \mathbf{R}$ & Central angle & Girders Geometry \\
\hline \multirow{2}{*}{0.2} & $12^{\circ}$ & Straight Girder (SG) \\
\hline & $12^{\circ}$ & Curved Girder (CG) \\
\hline \multirow{2}{*}{0.4} & $23^{\circ}$ & Straight Girder (SG) \\
\hline & $23^{\circ}$ & Curved Girder (CG) \\
\hline \multirow{2}{*}{0.6} & $34^{\circ}$ & Straight Girder (SG) \\
\hline & $34^{\circ}$ & Curved Girder (CG) \\
\hline 0 & $\infty$ & Straight Bridge (SB) \\
\hline
\end{tabular}

Table 2. Materials Properties

\begin{tabular}{cc}
\hline & Concrete \\
\hline Compressive strength of concrete & $40 \mathrm{MPa}$ \\
\hline Modulus of elasticity & $31870 \mathrm{MPa}$ \\
\hline Poisson's Ratio & 0.2 \\
\hline Specific Weight & $25 \mathrm{kN} / \mathrm{m}^{3}$ \\
\hline
\end{tabular}

\subsection{Geometry}

Figure 4 shows the adopted cross section and their geometric characteristics, calculated using the CSIBridge v17 structural analysis software. The parameters in Figure 4 correspond to: (a) Area of the entire cross section (A); (b) Polar Moment of Inertia (J); (c) Moment of inertia in relation to the y-axis of the center of gravity (Iycg); (d) Moment of inertia in relation to the z-axis of the center of gravity (Izcg); (f) Section center of gravity's position, in the y direction (ycg) and (g) Section center of gravity's position, in the $\mathrm{z}$ direction $(\mathrm{zcg})$.

\begin{tabular}{|cccccc|}
\hline $\mathrm{A}\left(\mathrm{m}^{2}\right)$ & $\mathrm{J}\left(\mathrm{m}^{4}\right)$ & $\mathrm{Iy}_{\mathrm{cg}}\left(\mathrm{m}^{4}\right)$ & $\mathrm{Iz}_{\mathrm{cg}}\left(\mathrm{m}^{4}\right)$ & $\mathrm{Y}_{\mathrm{cg}}(\mathrm{m})$ & $\mathrm{Z}_{\mathrm{cg}}(\mathrm{m})$ \\
\hline 6.3250 & 0.1893 & 3.5641 & 122.8937 & 7.50 & -1.5293 \\
\hline
\end{tabular}

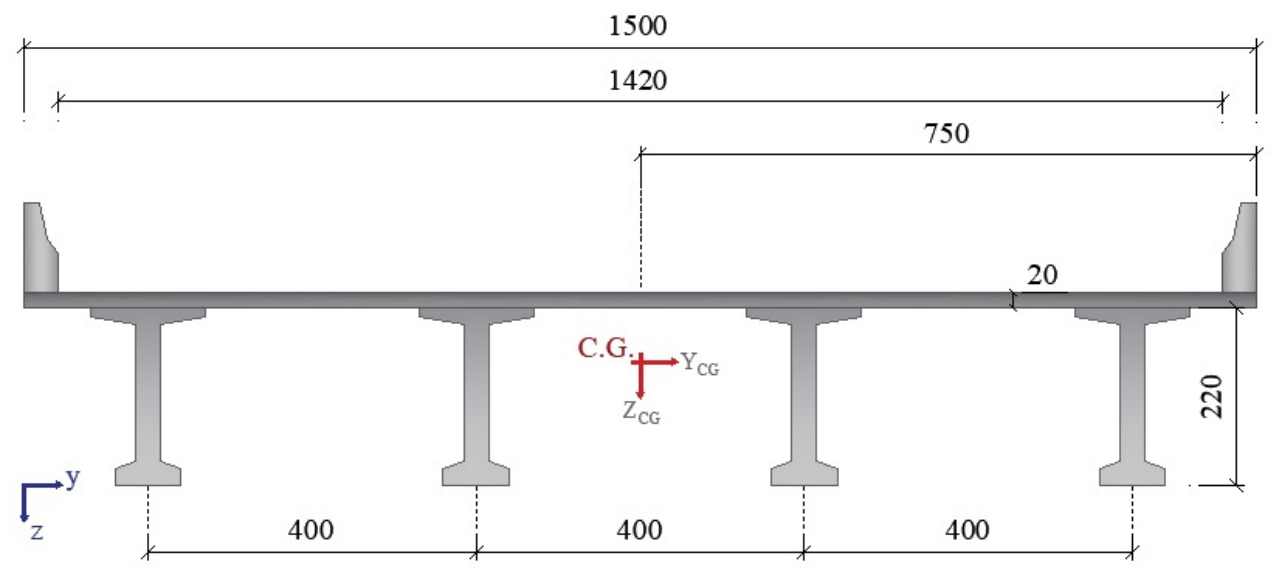

Centimeters

Figure 4. Cross section and geometric parameters. 
Regarding the evaluation of the stiffness of the cross-section, the paving surface of the bridge and the area related to the protective barriers were not considered. The cross-section has an overhang equal to 1.50 meters, measured from the axis of the outer beam to the ends of the slab.

In the curved bridge models, the longitudinal layout of the deck follows the center line ("layout line") of the bridge, maintaining a fixed radius. The girders were numbered from the external part to the curve, that is, the external girder was named G1 and the internal one G4 (Figure 5).

All models have a midspan diaphragm, measuring $1.80 \mathrm{~m}$ high and $0.30 \mathrm{~m}$ wide, due to the need for its insertion to ensure efficiency in the bending moment distribution and the overall balance of the structure.

\subsection{Bearings and boundary conditions}

The model used was the one proposed by Samaan et al. [9], maintaining the girders directly supported on the abutments using restricting only the vertical translation. Two of the girders have different restrictions (Figure 6). Thus, when evaluating the whole bridge, it is possible to consider an overall restriction of rotation of torsion, since all support devices prevent vertical translation.

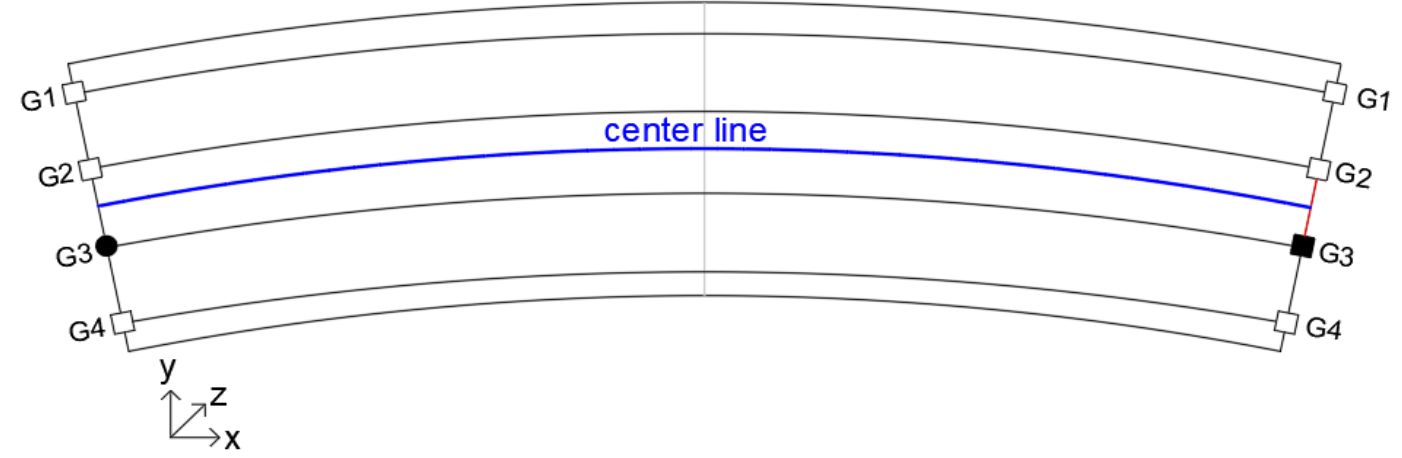

Figure 5. Bridge deck superior view and girder's identification.

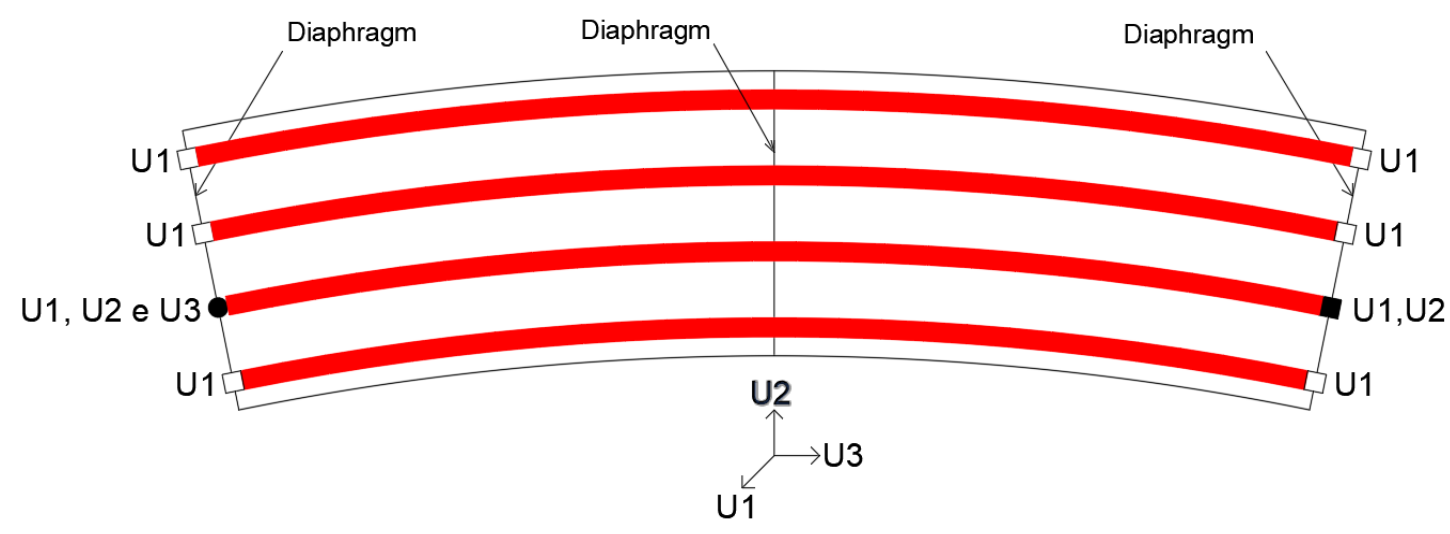

Figure 6. Boundary conditions.

\subsection{Load cases}

In this study two types of live loads were considered: the HL-93 (Figure 7) used by AASHTO [8] and the TB-450 (Figure 8) defined by ABNT NBR 7188 [10], applied to the deck using only mobile concentrated loads, without crowd loading. 


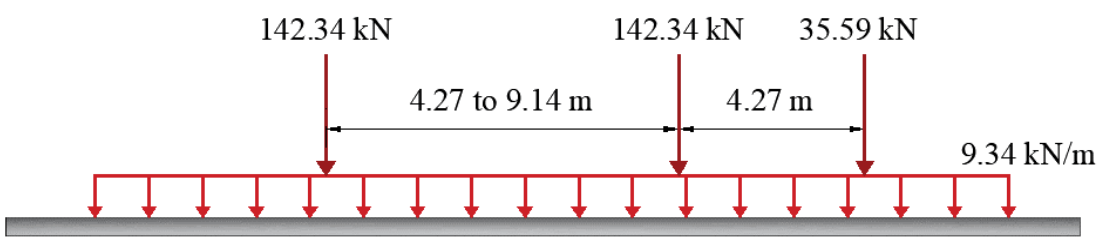

Figure 7. Vehicle type HL-93

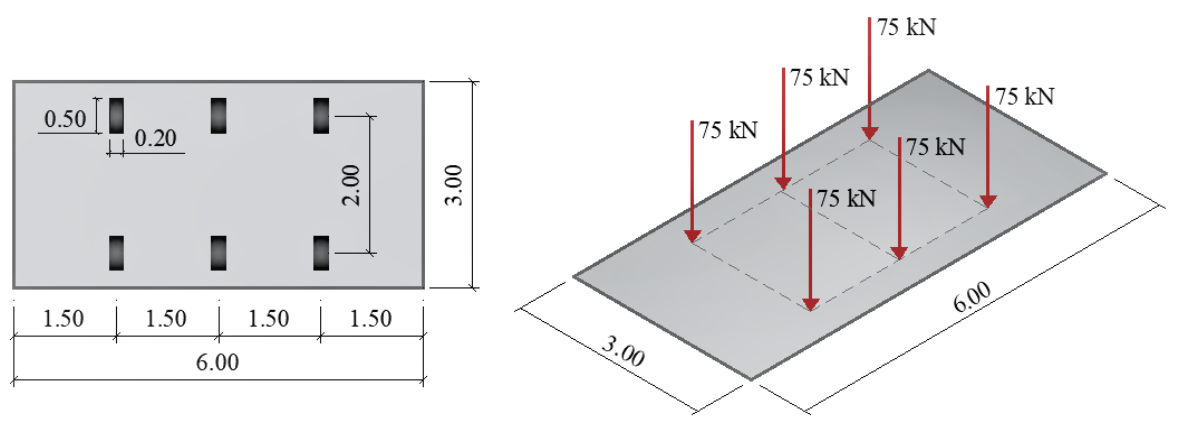

Figure 8. Vehicle type TB-450. Adapted by ABNT NBR 7188 [10].

To verify the impact of the passage of the vehicles in restricted regions, four types of load cases have been developed, named: general load case and load cases 01,02 and 03 . It should be noted that in the general load case, the vehicle-type walked, both in the transverse and longitudinal direction, all over the bridge deck. For this, a usual procedure of passing the vehicle type in the width of the load line predefined by the software CsiBridge v17 was used. A width of 14.2 meters respecting only the transverse application limitations of each standard vehicle was defined to delimit the crossing area of the vehicle. The general load case provided the bending moment envelops, from the influence surface. For this case, the maximum bending moment on the girders during the passage of the standard vehicle throughout the bridge was obtained.

In complement, to be able to compute exactly the bending moment portion captured by each girder in relation to the total obtained on the bridge, the vehicle-type was fixed in certain transverse positions, varying from position only along the length of the bridge. Each loading's position case can be seen in Figure 9.

\section{Load Case 01}

(a)

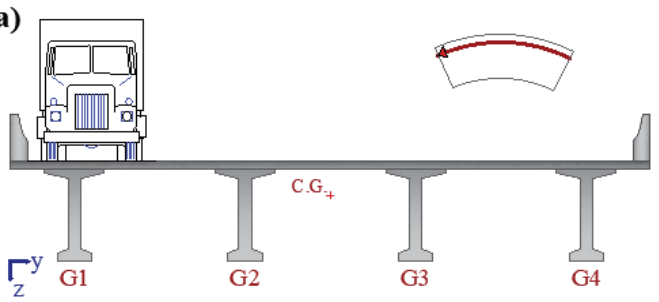

(b)

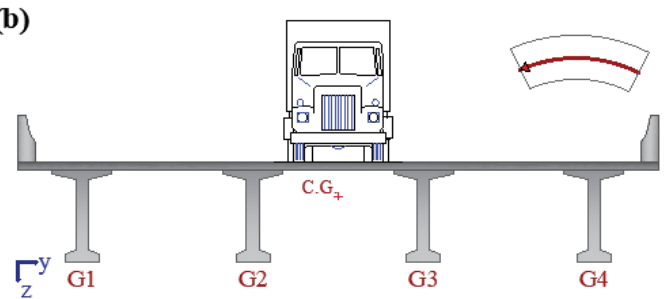

(c)

\section{Load Case 03}

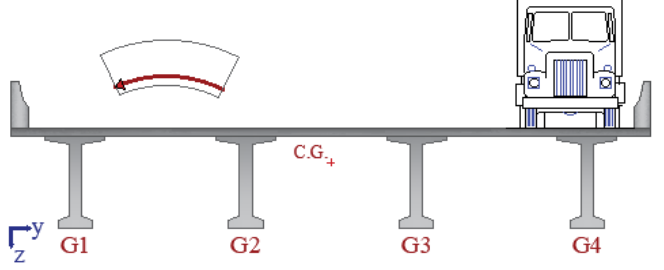

Figure 9. (a) Load case 01 - vehicle on the outside of the curve (b) Load case 01 - vehicle on the centerline of the curve (c) Load case 03 - vehicle on the inner side of the curve. 


\section{3D FEM MODELS}

The numerical modeling of this study (Figure 10 and Figure 11) was based on the 3D model proposed and validated by Cho et al. [5], similar to those proposed by Nevling et al. [11] in the level 2 model and by Kim et al. [7], which uses shell elements (four nodes and six degrees of freedom at each node) for the deck and frame elements (with two nodes and six degrees of freedom at each node) for the girders, connected by rigid links.

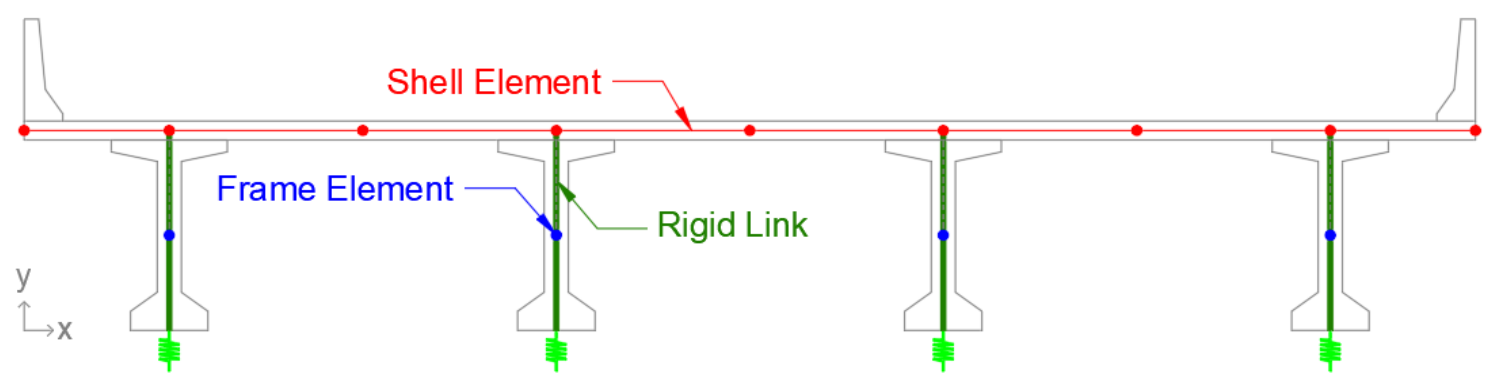

Figure 10. Numerical modeling discretization of bridge cross section.

The numerical modeling of this research was done with the CsiBridge v17 software. Since the aim was to analyze the bending moment transverse distribution in curved bridges, the decision was to use linear three-dimensional models, due to its good precision in relation to field tests, already tested by other researchers and mainly due to its capacity of concise visualization of the results.

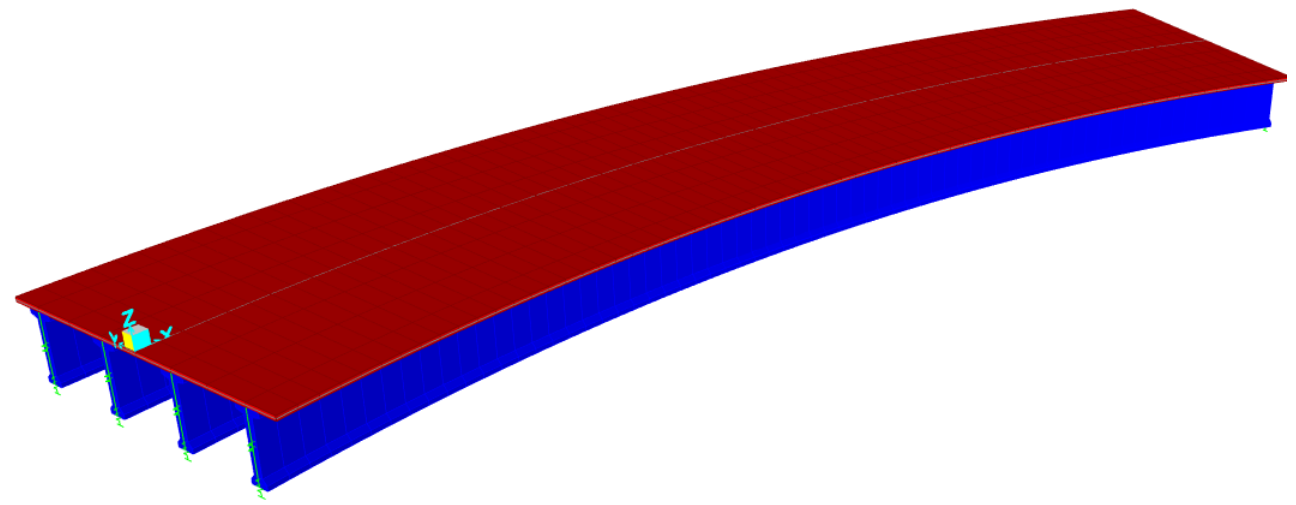

Figure 11. Example of a 3D finite-element bridge model used in the analysis

In all models a maximum element length of 1.20 meters in the longitudinal direction of the bridge was defined, maintaining the aspect ratio of the element at a maximum of 2.50 , since the use of smaller elements implied a high computational effort with low precision gains. Thus, the element length was within the limits suggested by $\mathrm{Fu}$ and Wang [12] and Fatemi et al. [13].

\section{PARAMETRIC ANALYSIS}

The results of the parametric analysis were determined in two methods: using the Modification Factor (MF) like that proposed by Acosta et al. [14], as well as the Bending Moment Distribution Factor (BMDF), calculated from the structural analysis of each model in the middle of the span. 


\subsection{Modification Factor (MF)}

The Modification Factor (MF) was obtained by the relationship between the maximum bending moment of the curved bridge on the study girder (Mc) and the maximum bending moment of the straight bridge on the study girder (Ms). This analysis factor aims to contribute as a design reference factor, where it would be possible to obtain an estimated maximum bending moment value in the curved bridge using the maximum moment obtained in a straight bridge model, with equivalent dimensions (same cross section and same span length).

$$
M F=\frac{\text { Max. girder bending moment }(\text { curved bridge })}{\text { Max.girder bending moment }(\text { straight bridge })}=\frac{M_{c}}{M_{S}}
$$

\subsection{Bending Moment Distribution Factor (BMDF)}

The Bending Moment Distribution Factor was calculated through the relationship between the bending moment results in the middle of the span (critical longitudinal section) for each girder, obtained through 3D models, and the bending moment results for the cross section, obtained through a spine model with equivalent stiffness, in the same critical section, submitted to the same live loads. This analysis method was used to understand the radial bending moment distribution for each bridge girder.

$$
B M D F=\frac{\text { Bending moment } \text { in the curved girder }}{\text { Total Bending moment }(\text { cross section })}=\frac{B M_{3 D, \text { girder }}}{B M_{1 D, \text { total }}}
$$

\section{PARAMETRIC RESULTS ANALYSIS}

\subsection{Global Analysis}

Initially analyzing the bending moment values in the global scope, an increase in the total bending moment (sum of the bending moments of the 4 girders) was observed in the models of curved bridge in relation to the straight line. In the examples studied, with an increase in the radius of curvature, the maximum bending moment in the middle of the bridge span was greater. The results obtained corroborate those found by Nevling et al. [11] and Cho et al. [5]. This is due to the portion of torsion coupled to the bending moment, arising from the balance formulations of a curved bridge. Thus, the torsion amplifies the bending moment making it larger than the bending moment in a straight bridge of the same total length.

Regarding the transverse position of the vehicle, it was observed from the load cases studied $(01,02,03$ and general) that the maximum bending moment values on the girders G1 and G2 occurred when the vehicle was in loading position 01 and on the girders G3 and G4 when the vehicle was in loading position 03 for all curved bridge models. That is, regardless of the radius of curvature, the loading migrated to the girders closest to it. This result guided the analysis, because it was possible to define the use of the general load case to obtain the maximum bending moment in the girders. On the other hand, the load cases 01,02 and 03 were used in the bending moment distribution analysis, to study the behavior of the bridge with respect to the radial distribution.

\subsection{Modification factor results comparison for curved and straight girders}

The difference in the Modification Factor (MF) between the two types of girders can be seen in the graphs of Figures 12-15, which show the curvature values on the horizontal axis and their corresponding MF value on the vertical axis. Figure 12 shows the values for the external girder (G1) and internal girder (G4) for the two types of girders geometry used in the curved bridge. In both cases a linear growth was observed in the MF value. For the external girders, the MF increases with the increase of the curvature (L/R), while for the internal girders, the MF decreases with the increase of the L/R. This behavior is consistent with the results found by Zhang et al. [15] and Acosta et al. [14]. Therefore, it was possible to verify that even with the application of different vehicle-types (TB-450 and HL-93) and with the use of different girders geometries (straight and curved) the behavior was maintained. 


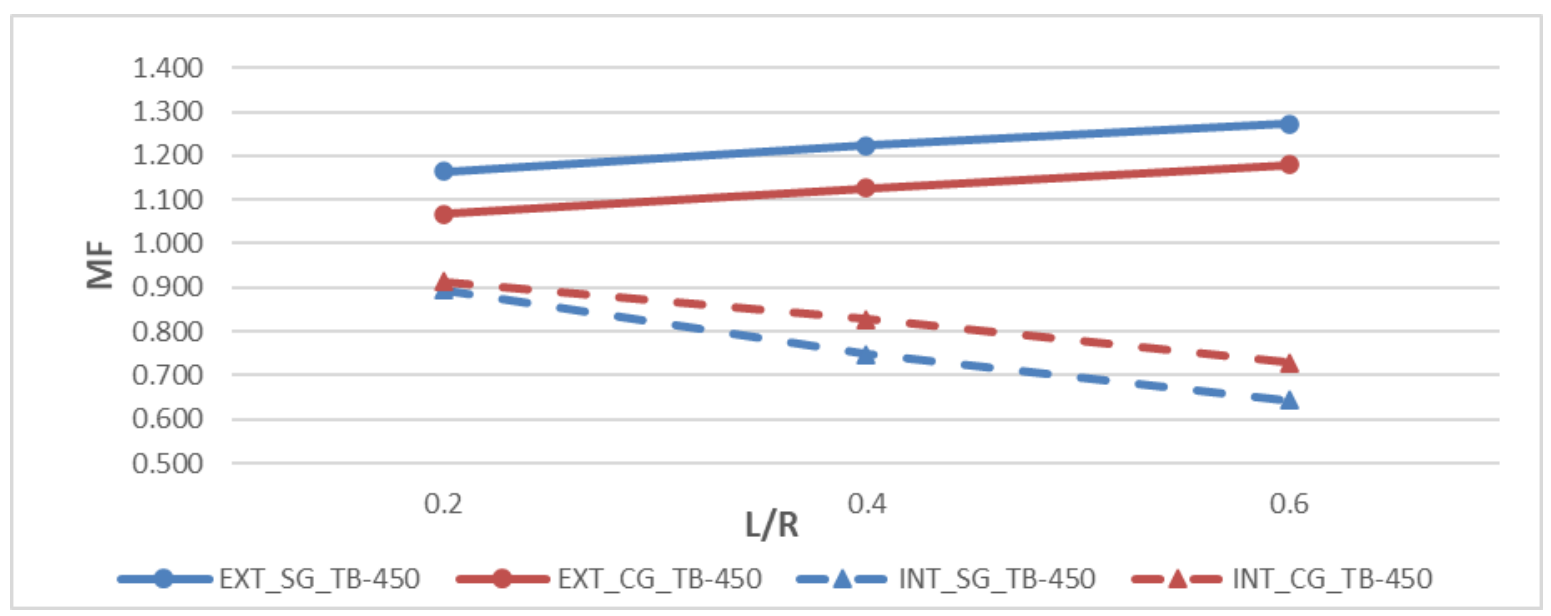

Figure 12. MF growth in relation to the external (G1) and internal (G4) girders.

The MF values for straight girders were higher than for curved girders. Figure 13 shows that the straight girder of the bridge with $\mathrm{L} / \mathrm{R}$ equal to $0.6 \mathrm{had}$ an $\mathrm{MF}$ equal to 1.273 . A difference of approximately 0.10 was then observed between the girders with the same corresponding $L / R$. This difference is probably due to the greater overhang in the straight ones, which increases the negative bending moment in the deck slab, boosting the torsion in the outer girder. The latter is considerably impacted due to the coupling between torsion and bending moment. This indicates that the use of straight girders in bridges with curved layout can have a higher material consumption than the use of curved girders, for all the usually practiced radius, since from the maximum bending moment the passive and active reinforcement of the girders are dimensioned. In addition, this increase in consumption will be multiplied by four, since all the elements of the bridge will be sized for that same maximum bending moment, resulting in a significant reflection in the total cost of the bridge.

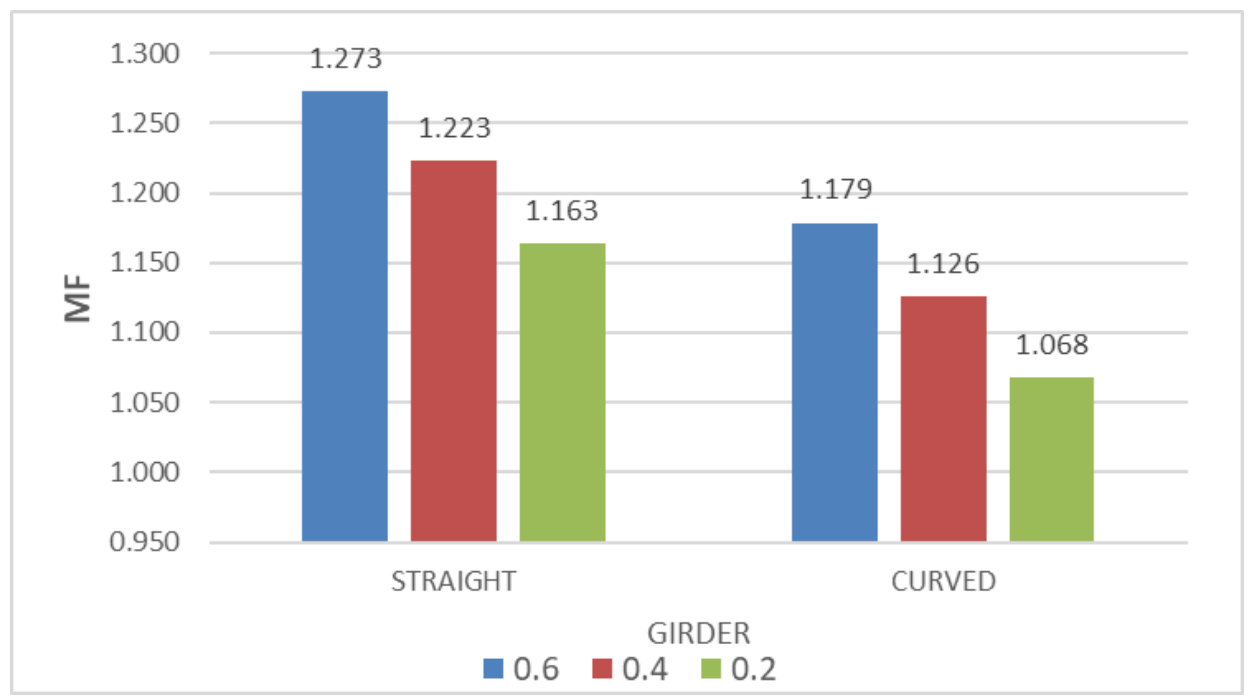

Figure 13. MF growth with vehicle type TB-450 for the most loaded girder (V1).

\subsubsection{Comparison between HL-93 and TB-450 using the Modification Factor (MF)}

The maximum values of the Modification Factor (MF) for all bridge models were compared with the HL-93 and TB-450 vehicles. The graphs in Figures 14 and 15 show the values found for the vehicle type HL-93 as well as the comparison between the values obtained for both. 


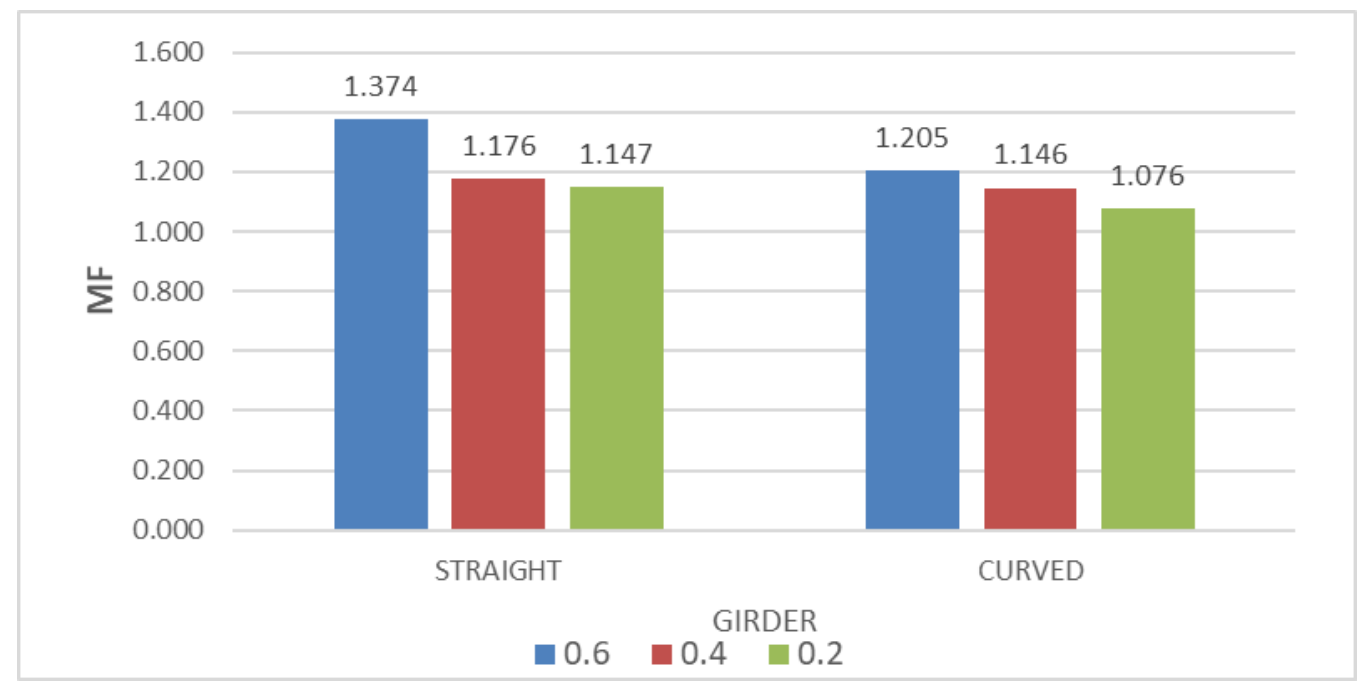

Figure 14. MF growth with vehicle type HL-93 for the most loaded girder.

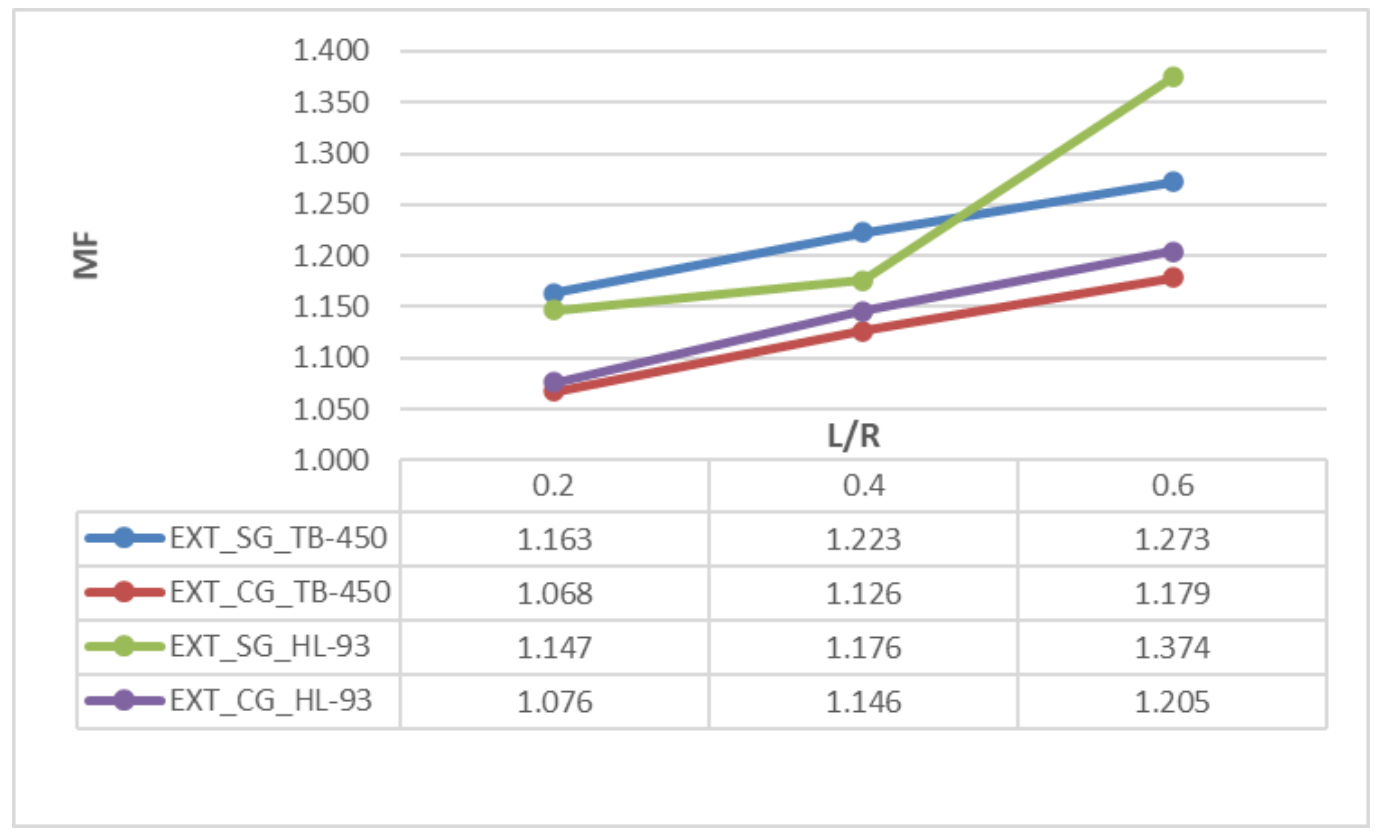

Figure 15. Comparison between HL-93 and TB-450 for the most loaded girder (V1).

It was found from these results that HL-93 generally provided greater bending magnitudes than TB-450. Moreover, the growth of the MF values for the HL-93 did not remain linear for the cases of L/R studied, however, in all results, the values of $\mathrm{MF}$ were higher for $\mathrm{SG}$ in relation to $\mathrm{CG}$.

\subsection{Bending moment distribution for the girders (BMDF)}

To analyze the bending moment distribution for the girders and later compare the structural behavior between straight and curved girders, the vehicle was positioned at both ends (load cases 01 and 03 ) and at the center of the bridge (center of gravity of the cross section), load case 02. The Bending Moment Distribution Factor (BMDF) was used as parameter.

For load case 01 (Figures 16-18) the BMDF values for girders G1 and G2 in the curved bridges were higher than those obtained in the straight bridge. For girders G3 and G4, there was a reduction in BMDF values in relation to the straight bridge. Except for the girder $\mathrm{G} 3$ for $\mathrm{L} / \mathrm{R}=0.4$ and 0.6 , there was a small increase of $\mathrm{BMDF}$ in relation to the 
straight bridge. A greater uniformity was also observed (less difference between girders) in the BMDF values for CG, when compared to SG, mostly between girders G1 and G2 (Figure 19).

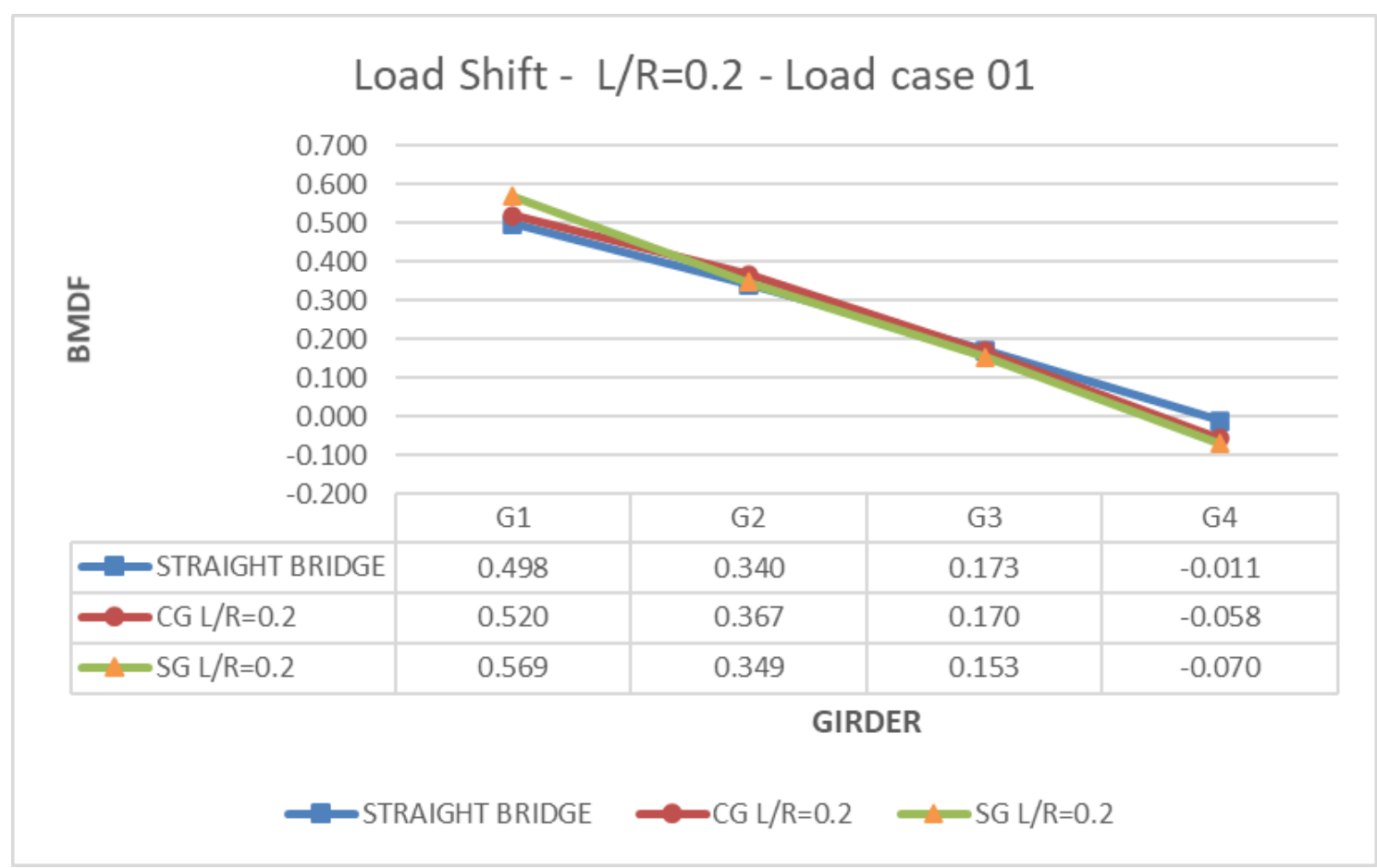

Figure 16. BMDF comparison between straight-bridge girders and curved and straight girders of 0.2 curvature and load-case-01-bridges.

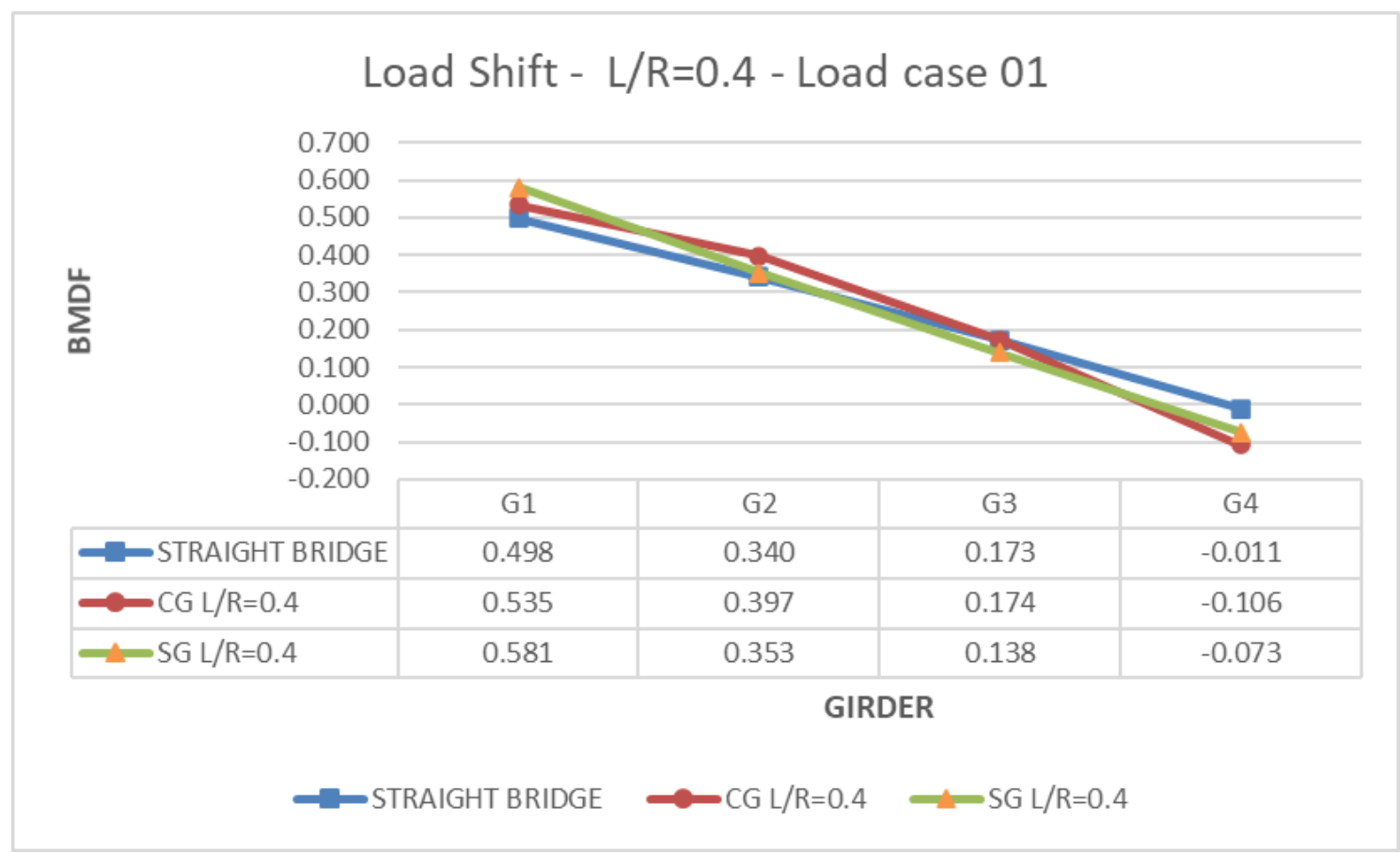

Figure 17. BMDF comparison between straight bridge girders and curved and straight girders of 0.4 curvature and load case 01 bridges. 


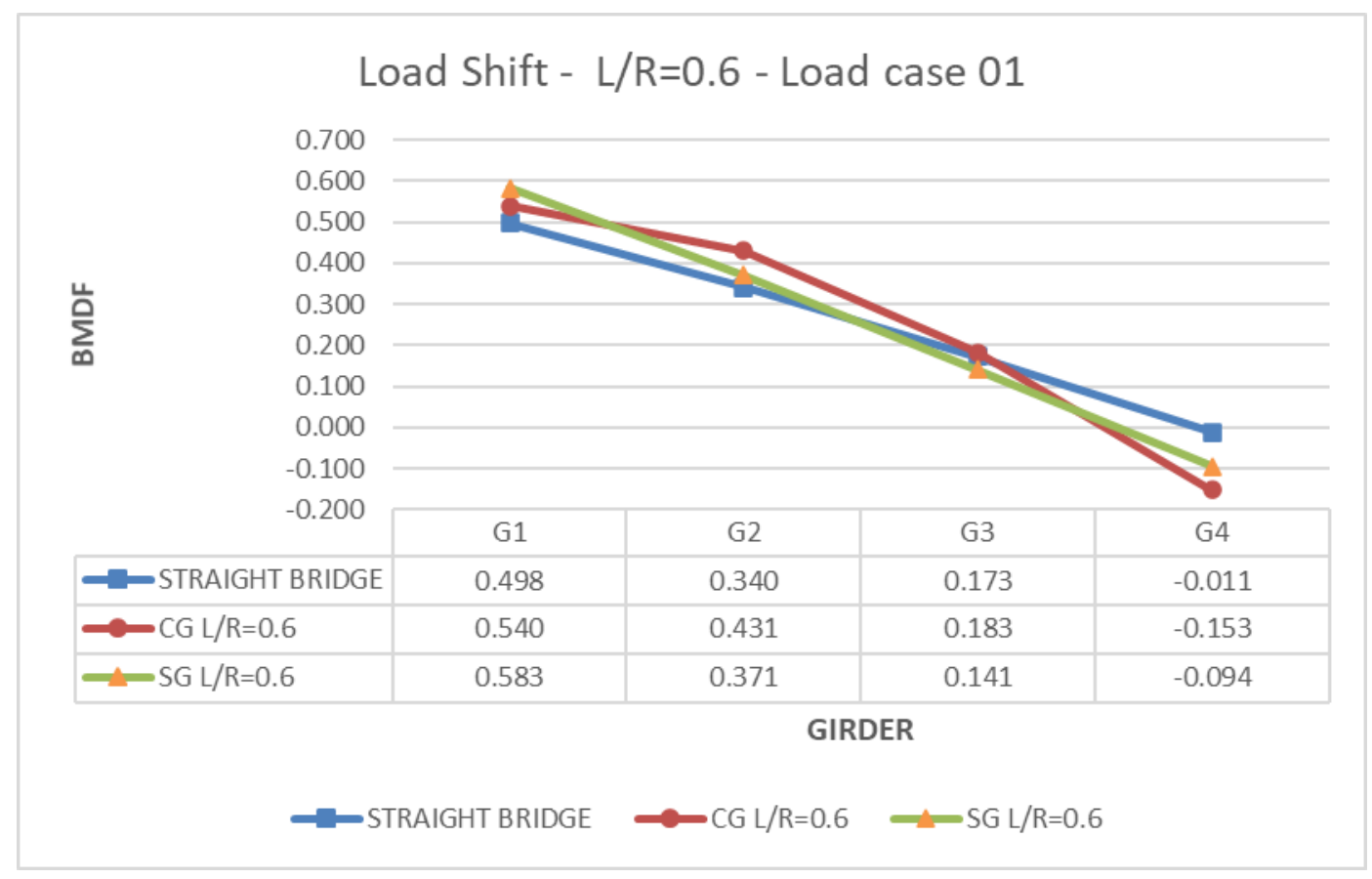

Figure 18. BMDF comparison between straight-bridge girders and curved and straight girders of 0.6 curvature and load-case-01-bridges.

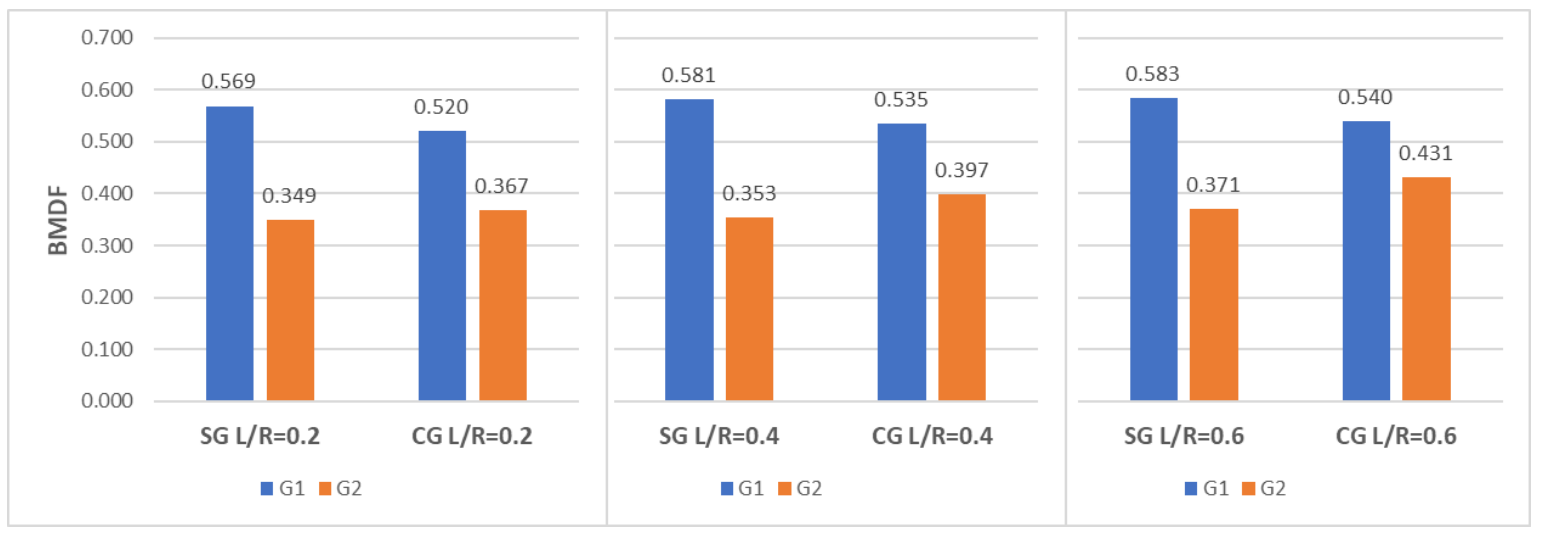

Figure 19. BMDF comparison between straight and curved girders for all studied curvatures.

In load case 03 (Figures 20-22) a different behavior from load case 01 was observed, as the BMDF values on the girders closest to the vehicle crossing region (G3 and G4) were reduced compared to the BMDF values on the straight bridge. Moreover, it was observed that with the increase in curvature a reduction in BMDF of G3 and G4 and an increase in G1 and G2 occurred. This structural behavior is not observed in bridges with straight geometry and needs attention, considering that in curved bridges with heavy curvature a tendency of uniformity may occur between the BMDF of all the girders of the cross section, even with a vehicle fixed in the inner region of the curve.

Still relative to load case 03, it was found that the BMDF values for the SG external to the curve (G1 and G2) were higher than the BMDF of the CG for all curvatures studied. In the internal stringers (G3 and G4) the opposite behavior was observed. This confirms the tendency already observed in the Modification Factor (MF) analysis, where the SG presented maximum bending moments higher than CG in these girders. In a certain way, it establishes a relationship between the two types of analysis with different parameters. 


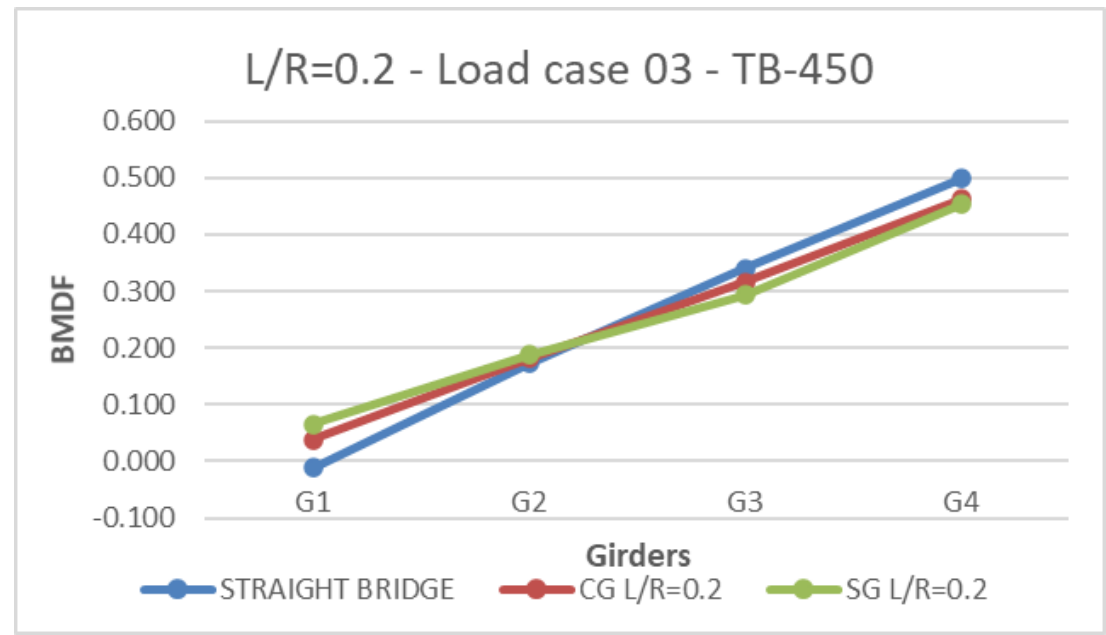

Figure 20. BMDF Comparison between straight bridge girders and both straight and curved girders from 0.2 curvature bridges on load case.

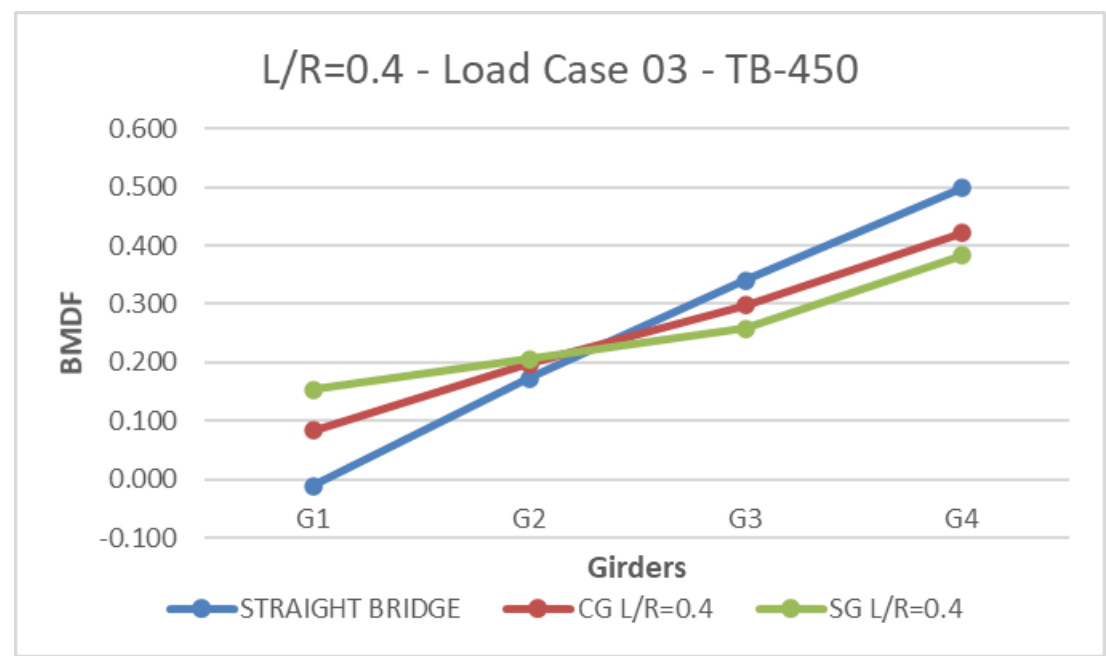

Figure 21. BMDF Comparison between straight bridge girders and both straight and curved girders from 0.4 curvature bridges on load case.

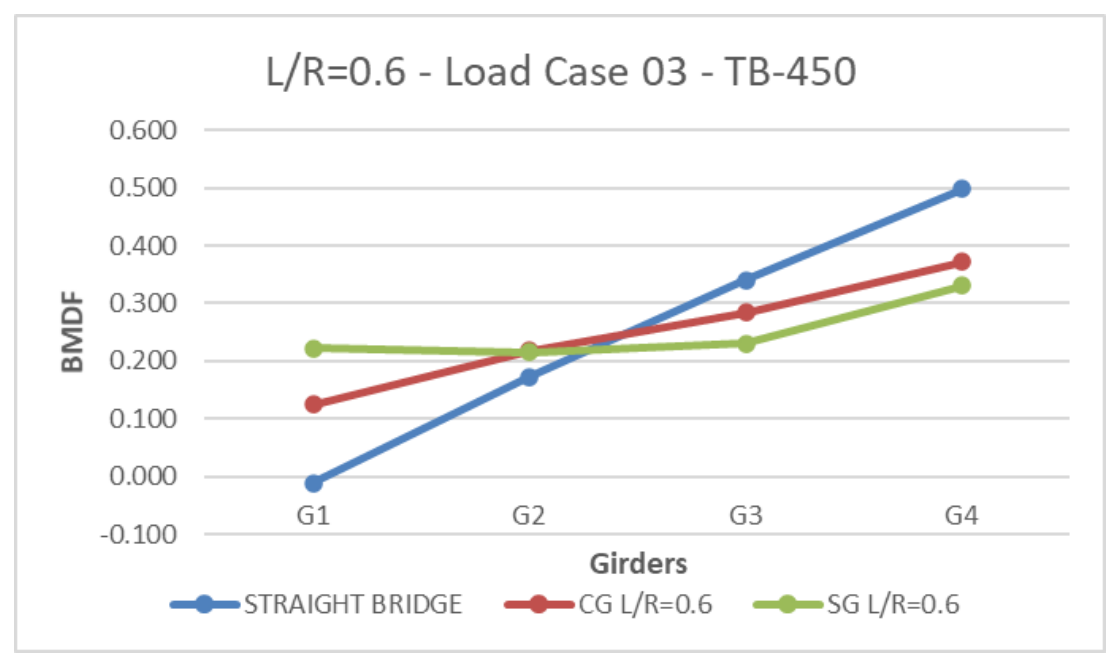

Figure 22. BMDF Comparison between straight bridge girders and both straight and curved girders from 0.6 curvature bridges on load case 03 . 
On the load 02 case for the straight bridge, it was found that approximately $25 \%$ of the total bending moment of the bridge was distributed for each of the girders, that is, there was an equal distribution. However, as shown in Figure 23, when we observed the studied curve bridge models the largest portion of the bending moment is intended for the external girder (G1), which corresponds to the studies of Kim et al. [7], Barr et al. [16] and Acosta et al. [14]. This probably occurs due to the eccentricity in relation to the center of gravity of the deck; the greater length of this girder in relation to the others, and the greater portion of area around its extension.

Moreover, from Figure 23 it was observed that there was an increase in the portion of the bending moment in the outer girder with the increase in the curvature. In the curved bridge with lower $L / R$, for example, there was an increase of $4 \%$ in the bending moment in the outer girder, even with an increase in the total bending moment of only $2 \%$.

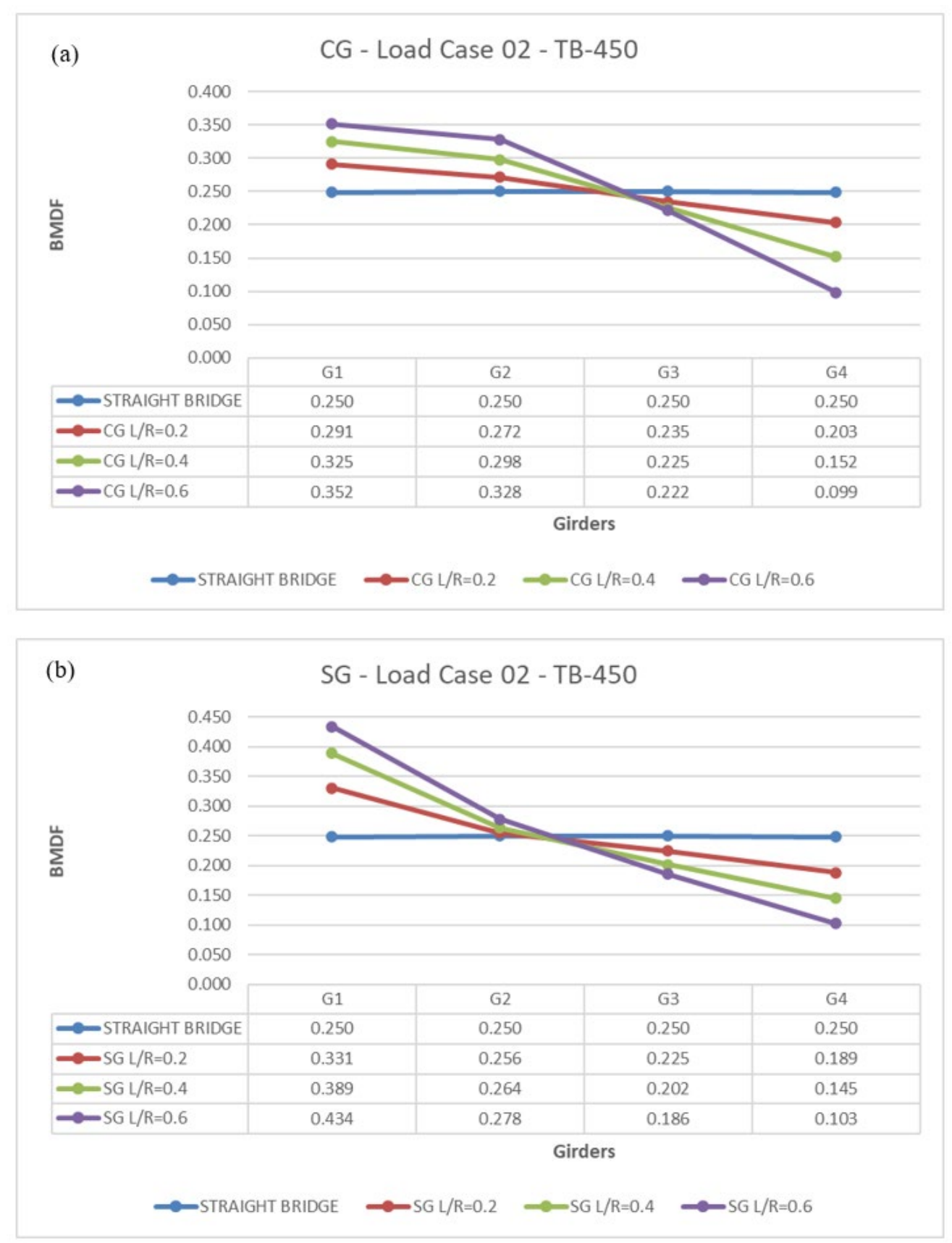

Figure 23. BMDF variation with curvature. Load Case 02 (a) Curved girders, (b) Straight girders. 
This confirms the occurrence of Load Shift in curved bridges for the bending moment, as emphasized in Guidelines for steel girder bridge analysis [17]. However, observing the results found, a rigid body behavior was not obtained, considering the differentiated variation of the bending moment for the external girder G1.

For this placement, it was observed a considerable difference in structural behavior between the straight and curved girders, considering that in SG there was a significant difference in bending moment between the girder G1 and G2 for all curvatures, which did not occur for CG. One can observe on Figure 24 , for $\mathrm{L} / \mathrm{R}=0.6$, a difference of $17.8 \%$ between the straight girders G1 and G2, while for the curved girders, the difference was only $6.6 \%$. In addition, it was observed from Figure 24 that there was a reduction of this difference with the reduction of the curvature. This structural behavior is quite favorable for CG, because a more uniform bending moment distribution is obtained between the girders, mainly regarding the condition of the bridge in service, aiming at the maintenance and prevention of cracks.

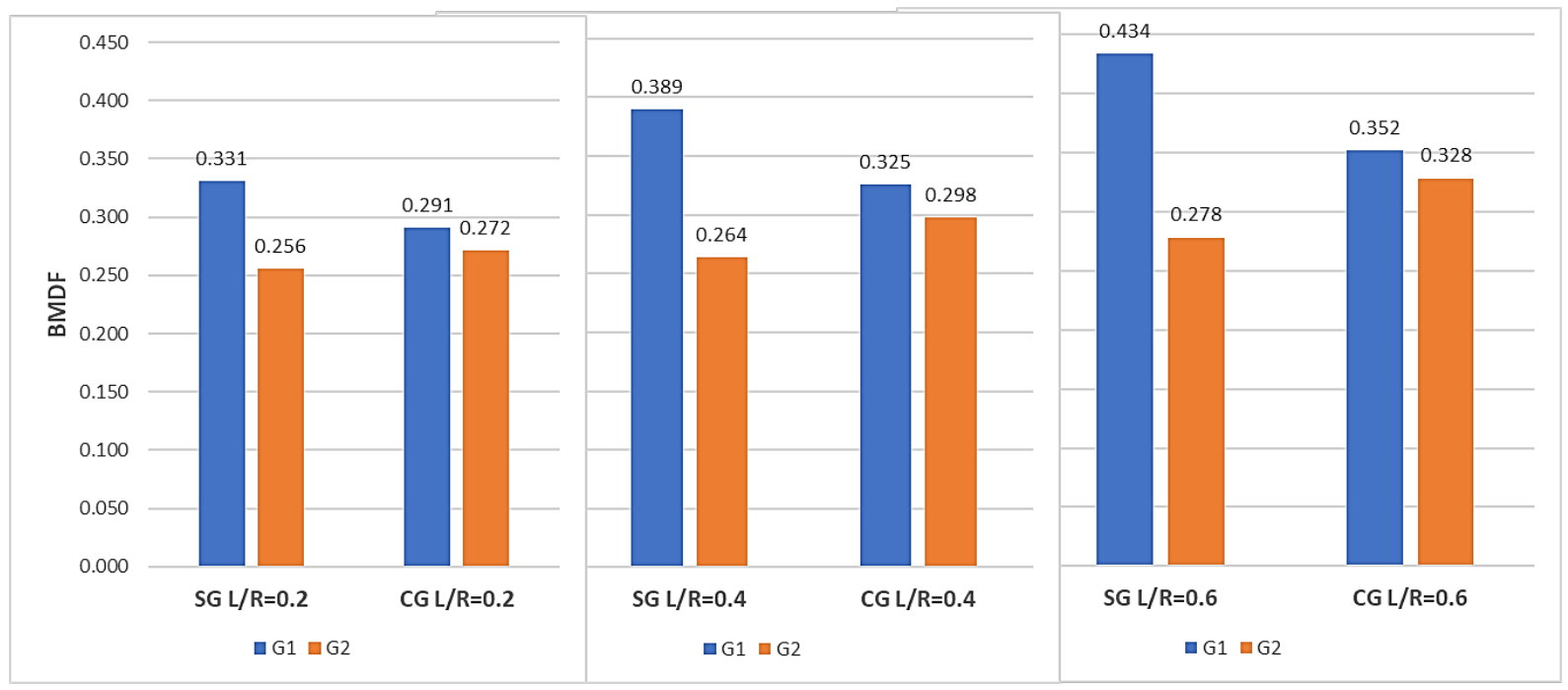

Figure 24. BMDF Comparison between straight and curved girders (V1 and V2) for all studied curvatures on load case 02.

When the relationship of this impact on all the cross-sectional beams was assessed, the graphs of Figures 25-27 were obtained, which show the bending moment distribution for bridges with SG and CG of the same L/R, comparing them with the straight bridge.

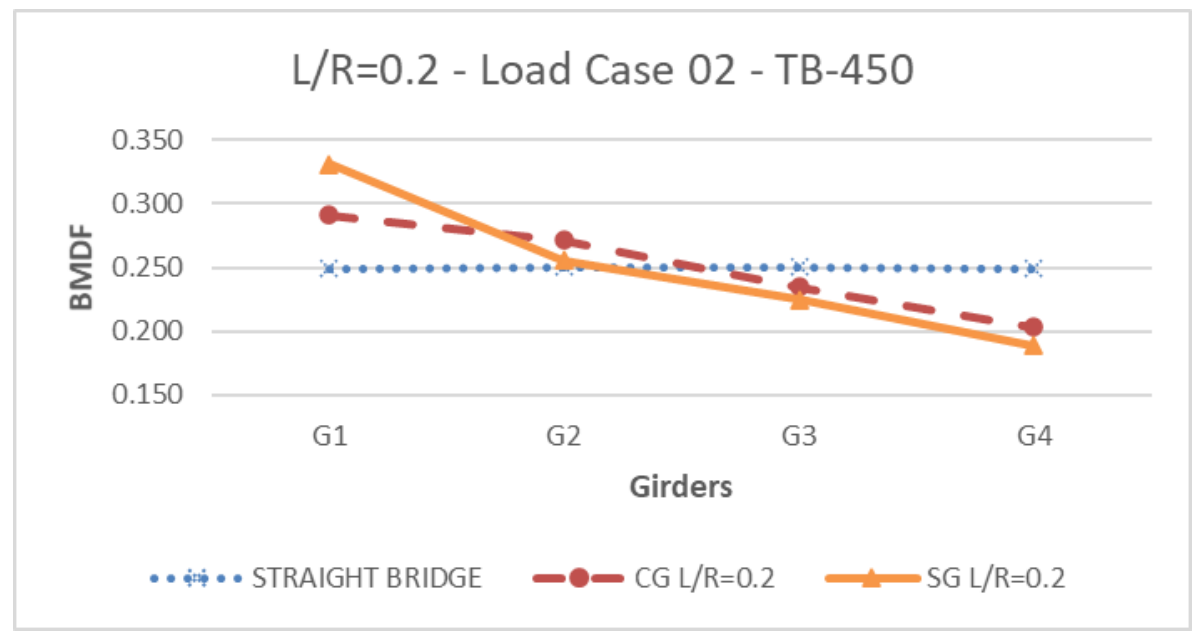

Figure 25. BMDF comparison between straight bridge girders and curved and straight girders from 0.2 curvature bridges on load case 02 . 


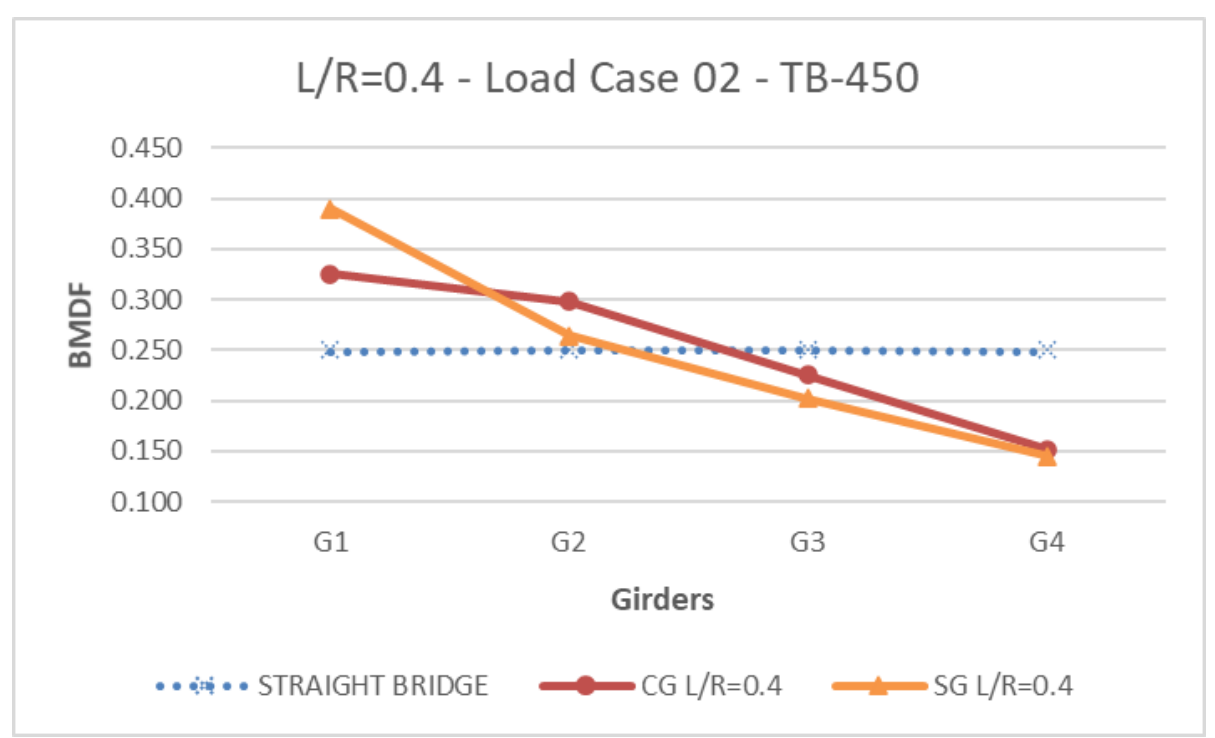

Figure 26. BMDF comparison between straight bridge girders and curved and straight girders from 0.4 curvature bridges on load case 02 .

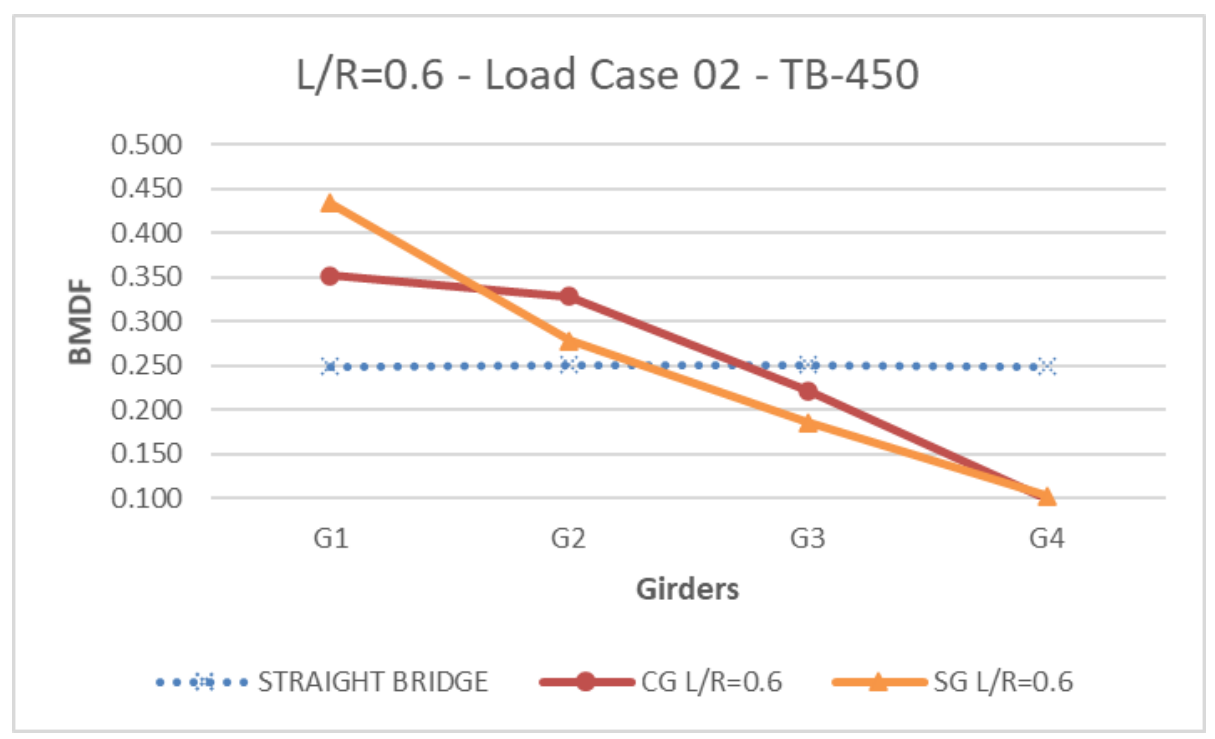

Figure 27. BMDF comparison between straight bridge girders and curved and straight girders from 0.6 curvature bridges on load case 02 .

\subsubsection{Comparison between HL-93 and TB-450 using MF}

BMDF results for HL-93 were also analyzed and compared with those obtained by TB-450 (Figures 28-30). For all curvatures studied, as well as the two types of girders (SG and CG), the values obtained for G1 with HL-93 were higher than those obtained with TB-450. However, for the other girders the behavior of the bending moment distribution between the two types of vehicles underwent variations without a clear observable tendency.

As the load shift of the bending moment to the external girders on the curve, it was found that this behavior was maintained even with the use of HL-93, since even applying the loading to the central line of the bridge (middle of the cross section), the largest portion of the bending moment found by BMDF was precisely for the G1, in all curvatures studied. Moreover, even in this study, where the distribution was studied, it was found that this portion of BDMF grew with the increase in curvature, which resembled the results of the trend for MF found previously. 

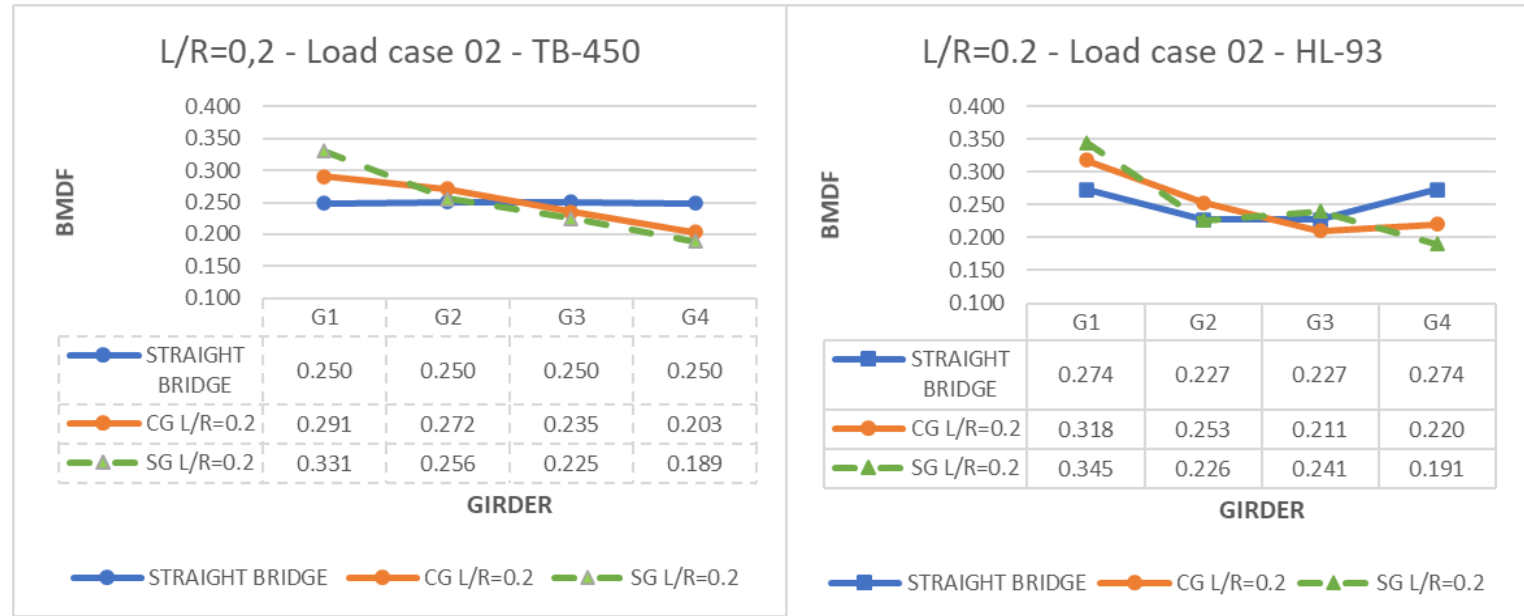

Figure 28. TB-450 and HL-93 comparison, load case $02, \mathrm{~L} / \mathrm{R}=0.2$.
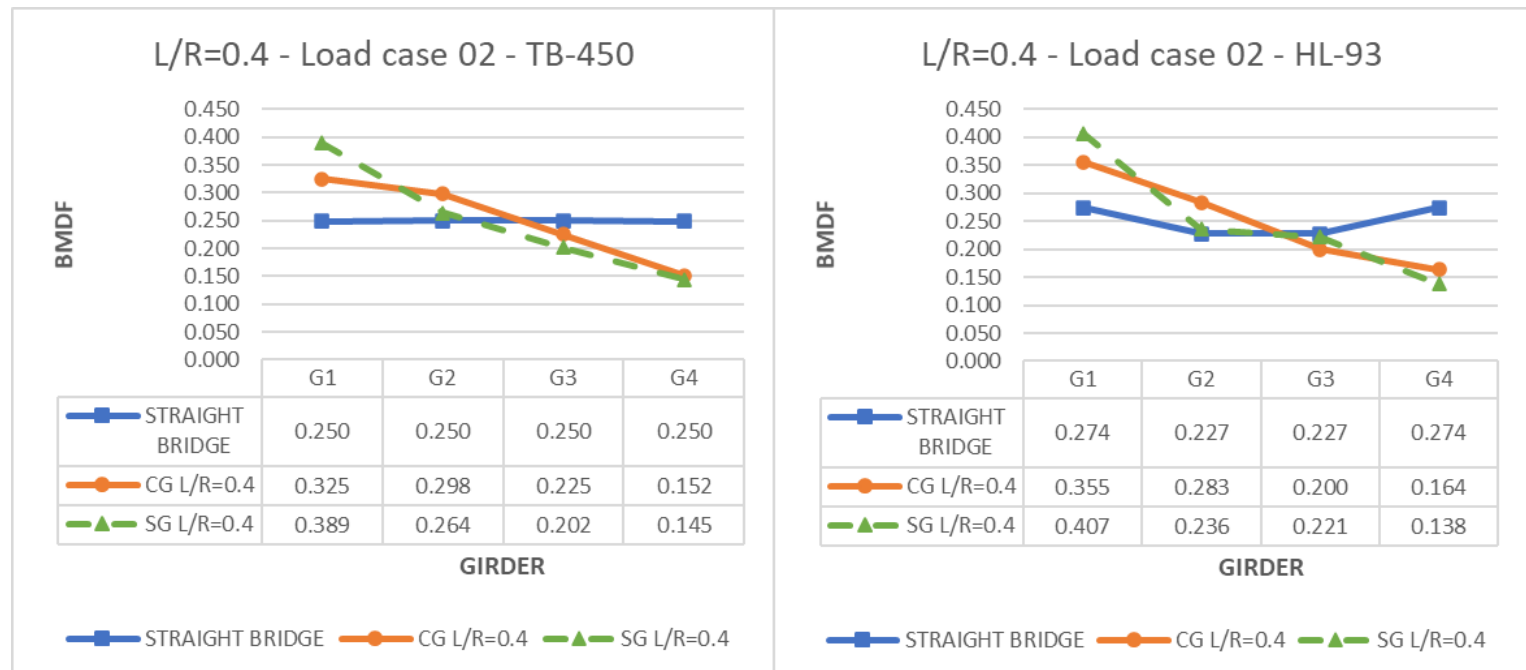

Figure 29. TB-450 and HL-93 comparison, load case $02, \mathrm{~L} / \mathrm{R}=0.4$.

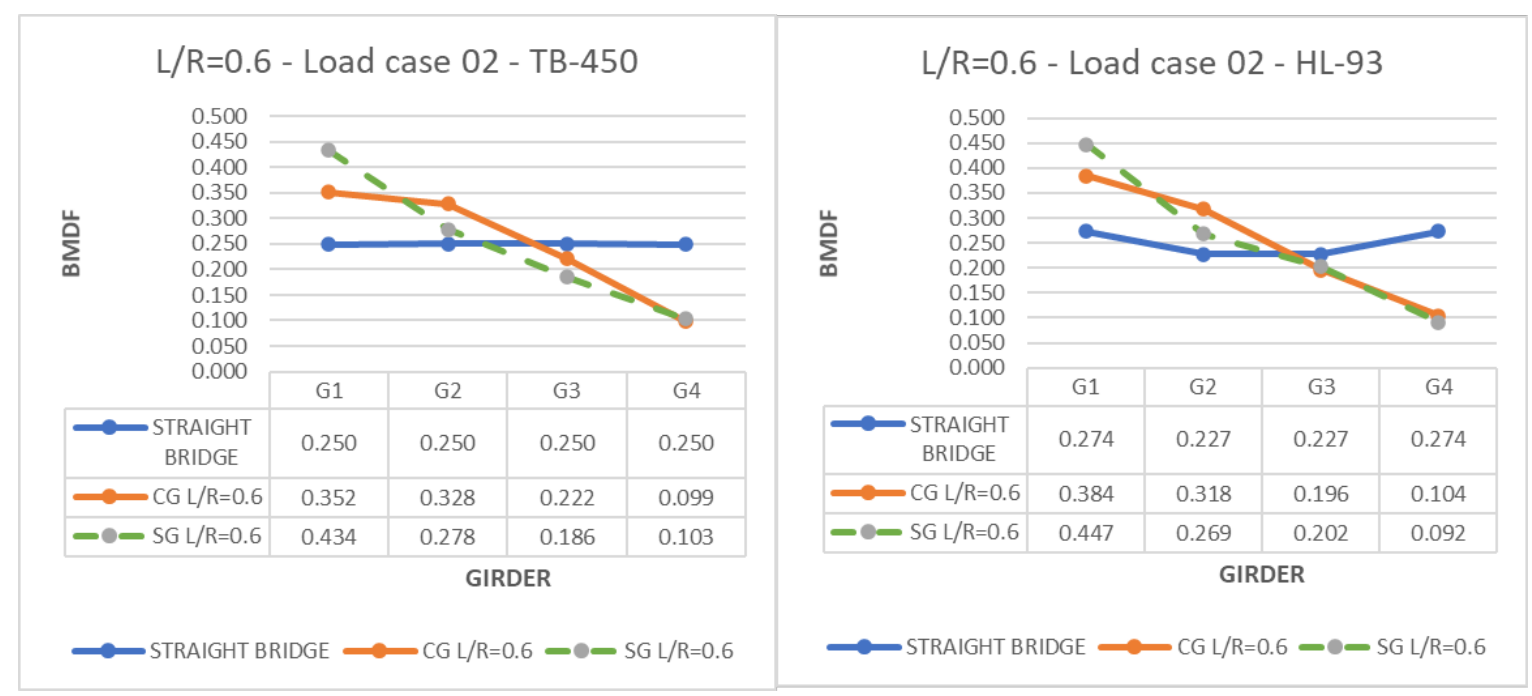

Figure 30. TB-450 and HL-93 comparison, load case $02, \mathrm{~L} / \mathrm{R}=0.6$. 


\section{CONCLUSION}

This article aimed to conduct a parametric comparative analysis of bridges with curved longitudinal layout comparing the transverse bending moment distribution, with straight and curved geometry girders. Three types of curvature $(0.2,0.4$ and 0.6$)$ were analyzed with the application of two different vehicle-types in four specific load cases (01, 02, 03 and general). Comprehensively analyzing the bridge, it was found that the maximum total bending moment in the cross section is higher in curved bridges than in straight bridges. However, this increase is unequally distributed for the girders, with the maximum bending moment always occurring in the outer beam (G1).

In analysis using the general load case, for both standard vehicles (HL-93 and TB-450), there is a gradual increase in the bending moment in G1 and a reduction in G4, with an increase in the curvature. In addition, it was found that the straight girders (SG) were underestimated at a greater bending moment than the curved girders (CG) in all curvatures studied. This statement points to a possible material saving when using curved girders, considering only the bending moment distribution, given the 0.10 difference in the MF value, which represents approximately a $10 \%$ difference in the bending moment value between these two girder geometries.

In the study of the bending moment distribution for the girders, using the case of load 02 , it was found that even with the application of the load on the central line of the board, the coupled effect of torsion with the bending moment, made the external girder (G1) the most requested in all curvatures studied. Comparing between SG and CG, a greater difference in bending moment was detected between the straight G1 and G2.

In short, considering only the bending moment distribution, it was possible to observe from the structural and economic point of view, from the results presented, that the use of curved girders in reinforced and/or prestressed concrete bridges with curved longitudinal design (curvatures between 0.2 and 0.6 ) is more advantageous than the use of straight ones. It is worth mentioning that for most detailed economic analysis, it would be necessary to extend the studies to other girder effects, such as torsion and shear.

\section{REFERENCES}

[1] World Economic Forum. “Annual Report 2015-2016.” WEforum.com. https://www.weforum.org/reports/annual-report-2015-2016 (accessed Mar. 3, 2020).

[2] W. Amorn, C. Y. Tuan, and M. K. Tadros, "Curved, precast, pretensioned concrete I-girder bridges," PCI J., vol. 53, no. 6, pp. 43-66, 2008.

[3] M. Alawneh, M. Tadros, and G. Morcous, "Innovative system for curved precast posttensioned concrete i-girder and U-Girder bridges," J. Bridge Eng., vol. 21, no. 11, pp. 04016076, 2016.

[4] Precast Concrete Institute, Bridge Design Manual, 3rd ed. Chicago: PCI, 2011.

[5] D. Cho, S. Park, and S. Hong, "Evaluation of girder distribution factor in PSC girder bridge with curved concrete slab based on AASHTO specifications," Arab. J. Sci. Eng., vol. 39, pp. 7635-7646, 2014.

[6] R. L. Brockenbrough, "Distribution factors for curved I-Girder bridges," J. Struct. Eng., vol. 112, no. 10, pp. $2200-2215$, 1986.

[7] W. S. Kim, J. A. Laman, and D. G. Linzell, "Live load radial moment distribution for horizontally curved bridges," J. Bridge Eng., vol. 12, no. 6, pp. 727-736, 2007.

[8] American Association of State Highway Transportation Officials, AASHTO LRFD Bridge Design Specifications, 8th ed. Washington: AASHTO, 2017.

[9] M. Samaan, K. Sennah, and J. B. Kennedy, "Positioning of bearings for curved continuous spread-box girder bridges," Can. J. Civ. Eng., vol. 29, pp. 641-652, 2002.

[10] Associação Brasileira de Normas Técnicas, Carga móvel rodoviária e de pedestres em pontes, viadutos, passarelas e outras estruturas, ABNT NBR 7188, 2013.

[11] D. Nevling, D. Linzell, and J. Laman, "Examination of level of analysis accuracy for curved I-Girder bridges through comparisons to field data," J. Bridge Eng., vol. 11, no. 2, pp. 160-168, 2006.

[12] C. C. Fu and S. Wang, Computational analysis and design of bridge structures. 1st ed. Boca Raton: CRC Press, 2015.

[13] S. J. Fatemi, M. S. M. Ali, and A. H. Sheikh, "Load distribution for composite steel-concrete horizontally curved box girder bridge," J. Construct. Steel Res., vol. 116, pp. 19-28, 2016.

[14] R. A. Acosta and J. V. González, "Structural Response of Plan-Curved Steel I-Girder bridges from an equivalent straight bridge analysis," J. Bridge Eng., vol. 23, no. 3, pp. 04017143, 2018.

[15] H. Zhang, D. Huang, and T. Wang, "Lateral load distribution in curved steel I-Girder bridges," J. Bridge Eng., vol. 10, no. 3, pp. $281-290,2005$.

[16] P. J. Barr, M. W. Yanadon, and M. Hailing, "Live-load analysis of a curved I-Girder bridge," J. Bridge Eng., vol. 12, no. 4, 477-484, 2007.

[17] American Association of State Highway Transportation Officials, Guidelines for Steel Girder Bridge Analysis. 2nd ed. Washington: AASHTO, 2016. 
Author contributions: AR: conceptualization, methodology, data curation, software, formal analysis, writing; JN: formal analysis, project administration, supervision, writing-review \& editing; RB: conceptualization, supervision, visualization; YN: data curation, writing-review \& editing; PC: conceptualization, visualization.

Editors: Luís Oliveira Santos, Guilherme Aris Parsekian. 